\title{
Cercles politiques et « salons » du début de la Révolution (1789-1793)
}

\section{Olivier Blanc}

\section{(2) OpenEdition \\ 1 Journals}

Édition électronique

URL : https://journals.openedition.org/ahrf/5983

DOI : 10.4000/ahrf.5983

ISSN : 1952-403X

\section{Éditeur :}

Armand Colin, Société des études robespierristes

\section{Édition imprimée}

Date de publication : 1 juin 2006

Pagination : 63-92

ISSN : 0003-4436

\section{Référence électronique}

Olivier Blanc, «Cercles politiques et «salons » du début de la Révolution (1789-1793) », Annales

historiques de la Révolution française [En ligne], 344 I avril-juin 2006, mis en ligne le 01 juin 2009, consulté le 22 avril 2022. URL : http://journals.openedition.org/ahrf/5983 ; DOI : https://doi.org/ 10.4000/ahrf.5983

Ce document a été généré automatiquement le 22 avril 2022.

Tous droits réservés 


\title{
Cercles politiques et « salons » du début de la Révolution (1789-1793)
}

\author{
Olivier Blanc
}

1 L'influence, le crédit et le début de reconnaissance sociale ${ }^{1}$ dont les femmes des classes nobles et bourgeoises de la société française bénéficièrent à la toute fin du XVIII ${ }^{\mathrm{e}}$ siècle, devaient subitement décliner avec la guerre totale et la politique de salut public qui en fut la conséquence. Durant cette longue période - de Valmy à Waterloo -, le pouvoir politique relégua aux oubliettes les beaux projets d'émancipation agités par Condorcet et Marie-Olympe de Gouges entre autres, et les nouvelles classes bourgeoises ne s'y intéressèrent pas comme en ont témoigné George Sand et d'autres femmes de la nouvelle génération. Si l'histoire a retenu que, pour les femmes, cette évolution fut une défaite en termes d'émancipation et de consécration légale de leur influence réelle, les documents issus des archives révèlent pourtant leur intérêt constant et leur participation active sous des formes inattendues et variées aux événements politiques de leur temps. Dans les archives des assemblées parlementaires, on relève un grand nombre d'interventions isolées ou collectives de femmes, souvent des pétitions, portant sur des questions d'intérêt général et non pas seulement des cas individuels. Faute d'avoir examiné de façon systématique ces documents comme ceux issus des différentes polices politiques, les archives judiciaires - celles des tribunaux d'exception $-^{2}$, faute aussi d'un dépouillement systématique des dossiers des sociétés populaires et des clubs où étaient enregistrées les interventions ou " prises de paroles » des femmes ${ }^{3}$, la postérité en a retiré qu'elles étaient demeurées indifférentes au débat et que si elles ont été représentées, ce fut par une poignée d'exaltées, ce qui est fondamentalement inexact. Il est vrai que les femmes avaient assez peu de "visibilité » dans la sphère publique, ce que Mme de Gouges, et d'autres comme elle, ont déploré en leur temps, mais il n'en demeure pas moins qu'elles conservèrent, de 1789 à 1793, une influence très forte dans la proximité des preneurs de décision et des meneurs d'opinion, notamment dans les cercles formés autour de femmes de la noblesse et de la bourgeoisie, souvent amies ou parentes de députés ou de ministres. Dans ces "sociétés " - le mot «salon » appliqué à ces assemblées, créé au XIX ${ }^{\mathrm{e}}$ siècle, n'existait pas encore ${ }^{4}$-, le poids de leur influence peut aujourd'hui être estimé par l'historien qui 
privilégie la documentation manuscrite aux imprimés en général - surtout si ce sont des écrits qui, publiés de nombreuses années après les événements, reconstituent sélectivement la réalité plutôt qu'ils en rendent compte comme dans le cas d'un journal ou d'une correspondance.

2 Pour peu qu'on les sollicite, les archives policières et judiciaires sont beaucoup plus exactes et éloquentes, allant fortement contre l'idée reçue selon laquelle les femmes animatrices ou habituées des salons et cercles politiques ont eu un rôle anecdotique et négligeable au prétexte qu'elles n'avaient pas de légitimité politique. Cette vision rétrospective du XIXe (dessinée par la plume des Michelet, Sainte-Beuve et Goncourt notamment) et de la première moitié du $\mathrm{XX}^{\mathrm{e}}$ siècle, tient beaucoup, croyons nous, à l'oubli ou à la méconnaissance des pratiques et mentalités du dernier quart du siècle des Lumières ${ }^{5}$. Il n'existe d'ailleurs à ce jour aucune étude digne de ce nom sur les cercles politiques et «salons" du règne de Louis XVI à la Restauration, et leur rôle aussi peu apparent qu'il était réel, quelque part entre les clubs et les assemblées élues, ou, aussi bien, dans l'histoire des alternances et des résistances politiques. On est ainsi frappé par la légèreté avec laquelle sont généralement traitées les deux dernières décennies du $\mathrm{XVIII}^{\mathrm{e}}$ siècle qui constituent des périodes charnières de l'histoire politique : loin de disparaître dans la «tourmente révolutionnaire ${ }^{6}$, les cercles n'ont ainsi jamais été aussi présents et actifs qu'ils le furent à cette période et particulièrement entre 1789 et 1793, puis entre 1795 et 1799 . Tous les documents d'archives - procès-verbaux de police ou de justice, correspondances diplomatiques ou journaux de voyageurs comme celui récemment publié de Wilhelm Von Humboldt ${ }^{7}-$ soulignent le rôle essentiel joué par ces cercles dans la sociabilité révolutionnaire parisienne, depuis les réunions organisées chez Mmes de Lameth, de Montmorin, de Staël à celles tenues au domicile de Lucile Desmoulins ou de Julie Talma, puis sous le Directoire chez Mmes de Condorcet, de Mun, d'Esparbès ou Regnaud de Saint-Jean d'Angély. Il n'est donc pas envisageable de parler de sociabilité et de mondanité au XVIII ${ }^{e}$ siècle sans prendre en compte le phénomène dans sa globalité spatiale et temporelle car le " monde des salons ", n'en déplaise à une tradition historiographique anti-révolutionnaire, n'a pas cessé en 1788. Au contraire, ils ont été des hauts lieux de l'opposition politique lorsque les partis qu'ils incarnaient étaient privés de représentation parlementaire et/ou persécutés, ainsi le parti constitutionnel après 1792 ou les mouvements royalistes du Directoire à l'Empire, et aussi sous la Restauration, époque pendant laquelle Mme Regnaud de Saint-Jean d'Angély qui animait un salon bonapartiste fut envoyée au secret à la Conciergerie puis expulsée de France (mars-juillet 1817) 8 .

3 Les préoccupations de ces cercles aristocratiques et bourgeois ont toujours été en phase avec la riche actualité pré-révolutionnaire et révolutionnaire, y compris depuis les années 1780 lorsque Louis XVI voulut obtenir la fermeture de la loge maçonnique, littéraire et artistique des Neuf-Sœurs, d'essence libérale, au prétexte de désordre, puis lorsqu'en 1787, il voulut s'en prendre aux clubs et cercles politisés du Palais Royal placés sous l'influence de l'anglophile duc de Chartres puis d'Orléans ${ }^{9}$. Dans ces cercles et salons libéraux du Palais Royal où l'on "préparait la révolution ", l'on donnait, certes, des concerts, on servait des repas et on jouait, mais surtout, on y pratiquait le brassage des classes et des idées, et bien entendu la mixité - une femme, souvent, faisait les honneurs des lieux -, que ce soit le salon des Princes, le club des Arcades de Goury de Champgrand et sa fille ${ }^{10}$, le club polonais du vicomte de Castellane, Lambertye 
et La Calprenède où Mme Grant, future princesse de Talleyrand faisait les honneurs en $179^{11} 1$, le club de Valois dirigé un temps par Palteau de Veymerange ou encore le club des étrangers fondé rue du Mail par le marquis Sanguin de Livry et qui se déplaça à la Chancellerie d'Orléans ${ }^{12}$. Dans les sociétés mondaines plus traditionnelles, essentiellement aristocratiques, également tournées vers la culture des arts et le jeu, la politique était, certes, constamment envisagée avec le sérieux nécessaire. Mais tandis qu'on se bornait, jusqu'aux années 1780 , à commenter les intrigues politiques chez Mme de La Reynière, à discuter les nominations de ministres chez Mme Doublet de Persan $^{13}$, sans trop songer à remettre en cause les oligarchies dans leurs principes et s'entendre sur le sens des mots "démocratie » ou "libéralisme", l'ensemble de ces cercles mondains de la fin des années 1780 évolua sensiblement, et leurs habitués se firent l'écho de questions financières comme les pensions abusives, la spéculation sur les actions des Indes ou l'immobilier parisien et autres scandales politiques comme l'affaire du cardinal de Rohan (1785) ou l'arrestation de Goislard de Montsabert et d'Eprémesnil en 1788, etc. Ils anticipèrent dès avant la Révolution les débats et questionnements des assemblées parlementaires successives qui votèrent les réformes à partir de 1789. Ils devinrent le prolongement de ces laboratoires d'idées qu'étaient les clubs formés dès 1787 , qui se multiplièrent en 1789 . On vit même des clubs politiques se tenir chez des particuliers comme ce fut le cas chez la baronne d'Aëlders qui recevait à son domicile rue Favart $\left(n^{\circ} 1\right)$ les membres des Amis de la Vérité (Claude Fauchet, Nicolas de Bonneville, etc. $)^{14}$, ou bien chez Mme Duval d'Eprémesnil dont l'hôtel de la rue Bertin Poirée fut, selon Malouet et Montlosier qui le fréquentèrent, un des hauts lieux de l'opposition monarchienne. Et les femmes, dans ces lieux, ne furent jamais les dernières à faire connaître leurs positions, s'appliquant aussi à favoriser les projets politiques qu'elles avaient à coeur de défendre. Il est impossible d'être exhaustif dans le cadre d'un seul article, quand bien même on se restreint aux cercles ou "salons » franciliens en activité pendant les quatre première années de la Révolution, plus ou moins réguliers et actifs selon les périodes ${ }^{15}$, avec des habitués portés par l'air politique du temps ou leurs convictions de principe, qui ne furent souvent pas les mêmes selon les époques. Il nous a cependant paru intéressant de resituer dans l'espace temps des trois premières législatures quelques-uns de ces «salons » franciliens, si tant est que le mot convient - on préférera le mot "cercle»-, en fonction des événements qui, de 1789 à $1793^{16}$, ont contribué à attirer l'attention publique sur eux, que ce soit la presse ou, surtout, les comités de surveillance - la police politique- des premières années de la Révolution.

Les cercles politiques privés du début de la Révolution

Dès le mois d'avril 1789, certains cercles de Versailles se sont appliqués à tuer dans l'œuf le «foyer révolutionnaire». Lorsque de premières listes de proscription imprimées circulèrent d'avril à juillet 1789 , on y remarquait entre autres les noms de femmes qui s'employaient à saboter la réunion des États généraux. La comtesse de Brionne, mère du prince de Lambesc célèbre pour sa charge à cheval, sabre au clair, dans les jardins des Tuileries, fut ainsi accusée d'avoir perçu des fonds importants de la Liste civile pour faire échouer la réunion des États généraux ${ }^{17}$. Les sociétés et coteries ultra - le " parti de la cour "-, très actives dans les mois qui précédèrent la réunion des États généraux, étaient principalement représentées, à l'hôtel Fortisson rue des Bons Enfants à Versailles, par la duchesse de Polignac née Yolande de Polastron ${ }^{18}$, elle-même entourée de sa belle-sœur Diane de Polignac ${ }^{19}$, de la comtesse Brunet de Neuilly née Beauchamp ${ }^{20}$ et de la comtesse d'Ossun née Grammont, plus particulièrement désignées 
dans les pamphlets sur les «manœuvres » de la cour en 1789. Sous l'influence de cette coterie dévouée à Marie-Antoinette et au comte d'Artois, Louis XVI décida d'abandonner Necker qui était devenu la bête noire des privilégiés.

Parmi les cercles «libéraux » dont on parlait beaucoup, c'est principalement celui de Mme Necker qui eut la plus grande réputation à la veille de l'ouverture des États généraux, en mai 1789. Depuis la mort de Mme Geoffrin ${ }^{21}$, le groupe formé par ceux qu'on appelait les philosophes s'était assez naturellement reformé chez Mme Necker née Suzanne Curchod, surtout connue pour sa bienfaisance et son mécénat caritatif elle a laissé son nom à un hôpital parisien -, mais beaucoup moins pour son engagement politique et son conservatisme sur les questions de société, notamment son hostilité au divorce. De chez elle sortaient, dit-on, une foule de libelles en forme d'apologie de son mari et dans certains, on crut reconnaître sa plume distinguée et son caractère susceptible ${ }^{22}$. Son cercle ou salon de la rue de la Chaussée d'Antin - ou à la belle saison au château de Saint-Ouen - accueillit en 1788 et 1789 des personnalités en vue dont Sieyès, Condorcet et Talleyrand qui jouèrent un rôle si décisif au début de la Constituante. Le jeudi, il y avait des réceptions publiques, presque officielles où Mme de Staël, fille de la maîtresse de maison, se fit connaître. Le mardi, c'était surtout des réunions littéraires où l'on voyait la duchesse de Lauzun, Delille et Lemierre. Un habitué, l'abbé Morellet rapporte qu'à onze heures, après que les domestiques avaient disparu et que les portes avaient été fermées, on débattait des questions politiques du moment. Quelques députés à la nouvelle Assemblée constituante y lurent des discours qu'ils devaient prononcer le lendemain ${ }^{23}$. L'administrateur général des finances, Necker, s'était largement appuyé sur le cercle d'intellectuels et d'écrivains réuni par son épouse pour soutenir sa réputation. Déjà révoqué deux fois, rappelé, portant sa démission à la main, il était devenu populaire grâce à l'hostilité que lui vouait le parti de la cour. Dix mois après son rappel aux affaires, sous la pression des ultras de la cour, Necker abandonnait la partie et son épouse reçut encore quelques semaines dans leur château de Saint-Ouen au nord de Paris. En perte de popularité depuis que, à la demande de Louis XVI, l'ancien ministre avait manifesté son hostilité à l'abolition des privilèges, le couple prit ensuite la route de la Suisse.

6 Les événements du 6 octobre 1789 qui entraînèrent le départ de la famille royale de Versailles et son installation au château des Tuileries, à proximité de l'Assemblée, furent perçus par les ultras comme un complot orléaniste dont les partisans se rassemblaient chez Mme de Genlis qui commençait à être citée en mauvaise part dans les journaux conservateurs. Barère et Brissot dans l'édition de leurs Mémoires ou Camille Desmoulins dans son journal le Vieux Cordelier, ont évoqué les réunions politiques qui avaient lieu chaque dimanche chez l'ancienne maitresse du duc d'Orléans devenue "gouverneur des enfants d'Orléans». Elle n'a jamais caché à ses contemporains son admiration pour le modèle politique anglais et c'est chez elle, dans son hôtel de la rue Bellechasse ${ }^{24}$, que s'était formée en 1787 la coterie orléaniste composée de son propre mari, le comte de Genlis (qui portait couramment le nom de marquis de Sillery), de son frère le marquis Ducrest, de Choderlos de Laclos, du duc de Biron ex-Lauzun, de Clarke, O'Shee, Mmes de Lachâtre et de Flahaut, et de quelques autres. Pourtant, Mme de Genlis, selon son principal biographe Jean Harmand, a copieusement révisé ce que fut son passé politique au début de la Révolution et l'influence bien réelle qu'elle eut sur le duc d'Orléans, au point qu'on ne peut s'appuyer sur ses écrits publiés après coup. De nombreux documents et témoignages sont en contradiction avec ce qu'elle affirme et lorsqu'en 1789, les partisans du duc d'Orléans 
n'excluaient pas que celui-ci pourrait être amené à devenir Lieutenant général du royaume, Mme de Genlis caressait assurément cet espoir. « Il est curieux de remarquer dès 1789, l'unité politique du Palais-Royal et de Bellechasse : bien que l'un soit devenu le fief de Laclos, l'autre étant le royaume de Mme de Genlis; tous deux se disputant le droit de gouverner à leur gré le mol, inconstant et instable duc d'Orléans, et par lui, de faire avec la fortune de la France, chacun la sienne propre $»^{25}$. Mme de Genlis - la citoyenne Brûlart - qui avait emmené ses élèves princiers (dont le futur Louis-Philippe) méditer sur les ruines de la Bastille, n'a probablement pas été étrangère aux événements du 6 octobre, même si la question est controversée. Après avoir participé avec ses élèves ${ }^{26}$ à un certain nombre de séances des clubs des Jacobins et des Cordeliers, attirant chez elle, dans son nouveau «salon jaune » de la rue des Mathurins, plusieurs de leurs membres dont Barère, Desmoulins, Robespierre mais aussi Pétion, elle se détourna tout à fait de la Révolution. À la suite des bruits de déchéance de Louis XVI après les événements dramatiques du Champ-de-Mars du 17 juillet 1791 et de la renonciation solennelle de Philippe-Égalité au trône ou à une quelconque régence, elle partit en émigration à Bath en Angleterre, en octobre $1791^{27}$.

7 Depuis la fin du règne de Louis XV, la tante de Mme de Genlis, Mme de Montesson occupait la chronique mondaine au titre de maîtresse puis d'épouse morganatique du duc d'Orléans père de Philippe-Égalité. C'est la protection qu'elle accorda aux gens de théâtre censurés qui a fait sa singularité et la réputation de ses réceptions régulières dans son salon somptueux de l'hôtel Montesson situé en vis-à-vis de celui d'Orléans, rue de la Chaussée d'Antin (rue de Mirabeau, $\mathrm{n}^{\circ} 70$ ) $^{28}$. Les témoignages de ses habitués font en effet état de la passion de Mme de Montesson pour le théatre, soutenant sans relâche les auteurs contre l'arbitraire des comédiens et des gentilshommes de la chambre du roi. Il y avait alors un certain nombre de femmes auteurs qui, comme elle, avaient créé un théâtre de société : Marie-Olympe de Gouges qui y joua ses propres productions ${ }^{29}$ et le revendit en 1787 au marquis de La Maisonfort, mais aussi Mme de Montalembert ${ }^{30}$, Mme de Salverte ${ }^{31}$ ou encore Mme de La Chabeaussière ${ }^{32}$ qui donnaient à jouer un répertoire assez favorable aux idées nouvelles. Mme de Montesson mit beaucoup d'espoir dans les travaux de la Constituante dont elle recevait plusieurs membres. Elle eut une sorte de passion pour Mirabeau et, à la mort du tribun, elle mit "le plus grand faste dans la douleur qu'elle témoigna " ${ }^{33}$. Connue pour une personne libérale et tolérante, consensuelle d'un point de vue politique, son attitude accommodante lui valut plus tard la bienveillance de Napoléon empereur.

Dans le même temps, un autre cercle "progressiste ", celui de Marie-Anne-Françoise ou Fanny Mouchard, comtesse de Beauharnais ${ }^{34}$, attirait ce que Paris comptait d'intellectuels favorables à la Révolution. Parmi les premiers spectateurs venus à la Comédie-Française le 4 novembre 1789 applaudir au triomphe de la pièce Charles IX, longtemps bloquée par la censure des gentilshommes de la Chambre du roi comme étant une critique de la monarchie, on remarqua Mme de Beauharnais qui avait toujours soutenu cette pièce "révolutionnaire " $^{35}$. En 1788, elle avait en effet organisé chez elle, dans son salon blanc de la rue de Tournon, actif depuis 1785 , situé non loin du palais du Luxembourg, une lecture du texte par Talma qui fut appelé à tenir le rôle principal de la pièce de Chénier. Son cercle fut des plus attractifs de la fin de l'Ancien Régime et on peut dire qu'il fut un des tout premiers "salons républicains ». Elle avait pratiquement toujours vécu séparée de son mari lui préférant la compagnie des gens de lettres, qu'elle protégea activement. Michel de Cubières dit Dorat-Cubières, son amant, fut un des co-fondateurs et animateur, avec l'astronome Lalande, de la loge 
maçonnique des Neuf-Sœurs. Moins connue comme auteur dramatique - une de ses pièces fut jouée au Français - que comme auteur de poésies anacréontiques qui lui ouvrirent les portes de plusieurs académies, Fanny de Beauharnais, ouverte aux idées nouvelles, accueillit la Révolution avec un enthousiasme très sincère. Ses réunions hebdomadaires étaient très suivies : "La Liberté et l'égalité sont les dames d'atour de Mme de Beauharnais » disait Michel de Cubières qui se signala lui-même par la suite pour son poème à la louange de Marat. Parmi les habitués de ce cercle, on cite l'auteur dramatique Cailhava qui avait à cœur de réformer les statuts de la Comédie française, Rétif de la Bretonne, Bailly ou Mme de Gouges dont les louanges furent chantées par Michel de Cubières $^{36}$. Tous les membres de la Loge des Neuf-Sœurs, du moins ceux qui avaient épousé le " parti patriote ", se retrouvaient aussi périodiquement chez Mme de Beauharnais et notamment Franklin, Mercier, Parny, Chamfort et quelques autres, auteurs et académiciens. Devenu secrétaire général de la Commune après le 10 août 1792, rejeté avec mépris par l'ancienne noblesse, Cubières était honni par les royalistes qui l'accusaient de trahison. Fanny de Beauharnais épousa ce discrédit, surtout de la part des émigrés, mais elle maintint tant bien que mal des réunions d'intellectuels et d'hommes et femmes politisés jusqu'en 1793, usant de son influence sur Cubières, à la Commune de Paris, pour épargner des suspects pendant l'année 1793: ainsi Mme d'Angivillier - qui animait elle-même un "salon » très conservateur -, ou l'abbé Morellet. Mais Cubières ne put intervenir pour Mme de Gouges dont l'affaire avait promptement été renvoyée au Tribunal révolutionnaire qui l'inculpa. Avec Mme de Beauharnais, il fut arrêté lors de l'épuration de la Commune hébertiste ${ }^{37}$.

Entre 1789 et 1792 , beaucoup de ceux qui fréquentaient la «société» de Mme de Beauharnais se rendaient aussi bien chez Mme de Villette qui partageait les idées de son mari, ancien protégé de Voltaire. Reine Rouph de Varicourt, baptisée "Belle et Bonne ", était une jeune femme de la noblesse du pays de Gex que Voltaire s'était autrefois mis en tête de proposer en mariage à son ami Charles de Villette, un homme sensible et cultivé qui se consacra à la littérature puis accueillit la Révolution naissante avec enthousiasme. Le couple, qui vécut en bonne harmonie, partageait le même culte pour Voltaire dont Villette réclama puis obtint de la Constituante le transfert des cendres au Panthéon en juillet 1791. Mme de Villette fit des apparitions publiques remarquées par la presse au cours des cérémonies qui marquèrent cet événement ${ }^{38}$, et son salon lambrissé et doré, situé dans un hôtel particulier situé à l'angle de la rue de Beaune et du quai Voltaire (jusqu'alors quai des Théatins), recevait d'anciennes relations de Voltaire comme le ci-devant marquis de Villevieille, mais aussi des personnalités favorables au régime républicain comme Cambacérès, et des journalistes, notamment les rédacteurs du journal la Chronique de Paris, journal auquel Villette collaborait avec Mercier, Clootz, Condorcet, etc.

10 Élu député à la Convention, l'ex-marquis de Villette stigmatisa publiquement les massacres de septembre puis, comme Condorcet, Boissy d'Anglas et autres républicains de la première heure, il s'opposa à la condamnation de Louis $\mathrm{XVI}^{39}$.

11 Un des premiers cercles républicains prit paradoxalement naissance chez une femme issue de la noblesse, Louise Félicité de Guynement de Kéralio qui eut un cercle très couru sous la Constituante où vinrent un certain nombre de membres des Jacobins et des Cordeliers. Née en 1758, petite-fille d'un maréchal de camp et nièce d'un chevalier de Saint-Louis ayant participé avec La Fayette à la guerre d'Amérique, elle était la fille de Louis-Félix de Kéralio, un homme lettré - comme l'était d'ailleurs sa mère née 
Marie-Françoise Abeille qui appartenait à une famille d'armateurs et de négociants marseillais en affaires avec Saint-Domingue ${ }^{40}$. Kéralio appartenait à l'Académie royale des Belles Lettres et il fréquenta la "société d'Auteuil», gardant des relations épistolaires avec Franklin après son départ de France. Il aida sa fille dans ses premiers essais au Censeur Universel où elle plaça des articles, puis celle-ci traduisit des ouvrages de l'anglais et de l'italien et se fit connaître avec son Histoire d'Elisabeth. Reçue en avril 1787 membre honoraire à l'Académie royale des Belles Lettres d'Arras, elle y lut un discours de remerciement qui, relate un contemporain, fut suivi par une réponse de Robespierre avec lequel elle resta en contact :

«Il félicita l'académie sur le choix qu'elle avait fait d'une personne aussi intéressante par les charmes de son esprit et par l'étendue de ses connaissances que par les grâces de son sexe. Il examina à cette occasion s'il était avantageux d'admettre les femmes dans les compagnies littéraires et prouva que l'introduction de cet usage serait utile aux femmes et aux académies et opérait par conséquent le bien public. $»^{41}$

Melle de Kéralio vivait chez ses parents, rue de Gramont $n^{\circ} 17$, à l'époque de son mariage le 14 mai 1790 avec l'avocat Robert dont elle partageait les idées avancées ${ }^{42}$. Écrivant avec plus d'aisance que lui, elle exprima leurs idées républicaines dans le Journal d'État et du Citoyen, devenu le Mercure national, avec la devise "Vivre libre ou mourir ». Si elle fit quelques apparitions dans les clubs, elle était néanmoins peu favorable à une visibilité des femmes dans la sphère politique, prenant l'exact contrepied de ce que réclamait Condorcet et Mme de Gouges. Ce faisant, elle se mit en contradiction avec elle-même, continuant de publier des écrits politiques sans trop chercher à déguiser son identité. Comme beaucoup de femmes politisées, elle reçut dans l'intimité de son cercle de la rue des Marais un certain nombre de personnalités politiques dont les époux Roland avec lesquels elle se brouilla par la suite, puis des députés de la Montagne ${ }^{43}$. Cependant, elle réagit vivement lorsqu'en 1793, le Girondin Louvet, dans son journal La Sentinelle écrivit qu'en 1791 «Robespierre et Marat se réunissaient chez Collot d'Herbois, plus souvent chez Robert, quelquefois chez Danton $»^{44}$. Mme Robert, dont les convictions politiques étaient devenues beaucoup plus flottantes après l'exécution de Louis XVI - le couple fut accusé d'entretenir des relations avec d'Orléans et Dumouriez -, réprouva la Terreur et, à la veille du vote de la loi des suspects (17 septembre 1793), les exemplaires du journal qu'elle co-dirigeait depuis avec son mari, L'Observateur, furent saisis, mais elle-même et ses deux rédacteurs ne furent pas inquiétés ${ }^{45}$. Quelques jours plus tard, Robert qui s'occupait toujours de négoce de denrées coloniales fut accusé d'accaparement. Bénéficiant de solides appuis politiques, il parvint à se justifier et le couple évita l'emprisonnement en l'an II.

Les résistances à la Révolution

Plusieurs des femmes royalistes dont l'influence auprès des preneurs de décision était réelle, durent émigrer au lendemain de la prise de la Bastille pour des raisons de sécurité. Mais on retrouve les autres - la grande majorité ${ }^{46}-$, toujours aussi politiquement actives dans quelques maisons particulières de Paris dont les habitués furent momentanément inquiétés après le 10 août 1792 et plus gravement après le vote de la loi des suspects un an plus tard. Plusieurs animatrices de cercles politiques de la Constituante et de la Législative devaient être arrêtées en l'an II, d'autres le furent sous le Directoire (autour du 18 fructidor an V), d'autres enfin après la rupture de la paix d'Amiens (1804) qui entraîna l'exil forcé d'une bonne centaine de femmes ${ }^{47}$. L'ouverture des dossiers de police de ces femmes, qui sont en très grand nombre (sous série F7 des 
Archives nationales) tend à prouver que les activités de ces cercles furent prises au sérieux par les gouvernements successifs mais sont demeurées inconnues à l'historiographie suiviste des auteurs du XIX ${ }^{\mathrm{e}}$ siècle. Un cercle politique assez actif dans la lignée ultra de celui de la duchesse de Polignac est celui de la ci-devant duchesse de Villeroy qui chercha à rallier l'aile droite de la Constituante à la cause monarchique et au retour à l'ordre ancien. Fin 1789, au moment où allait s'ouvrir le procès du marquis de Favras, le Comité des Recherches de l'Assemblée avait ainsi été saisi d'un projet d'enlèvement de la famille royale commandité par le maréchal de Maillebois et son amie la marquise de Cassini, belle-fille de l'astronome, qui tenait elle-même un cercle politique royaliste dans son hôtel de la rue de Babylone ${ }^{48}$. Les protagonistes de cette affaire parvinrent à émigrer, mais en octobre 1790 suivant, un nouveau projet d'enlèvement ou de fuite fut bientôt mis sur pied par un groupe à la tête duquel se trouvait Mme de Villeroy, épouse séparée de Louis Gabriel de Neuville, duc de Villeroy. Très engagée dans les affaires politiques, tenant ses réunions rue de l'Université, elle participait à la rédaction du journal les Actes des Apôtres ${ }^{49}$. Le Comité des Recherches de l'Assemblée constituante détourna un jour deux lettres faisant état de préparatifs d'un plan concerté d'évasion à Rouen de la famille royale, et dans ce projet, Mme de Villeroy était citée avec son propre frère, Louis-Alexandre de Villequier, lieutenant général gouverneur du Boulonnais, à demeure auprès de Louis XVI au château des Tuileries, et quelques députés de la droite radicale à l'Assemblée, c'est-à-dire Maury, Foucault, Cazalès entre autres. Ce projet semble n'avoir pas eu de commencement d'exécution mais les documents indiquent que Mme de Villeroy s'était personnellement chargée de la logistique et des relais, aidée en cela par un certain nombre de personnes dont le comte de Radepont qui avait mis son château à disposition pour accueillir les fugitifs. Ces premières tentatives d'évasion de Louis XVI et de sa famille vers la province et l'étranger furent souvent menées en concertation avec des femmes déterminées et élaborées dans les cercles royalistes ultra.

C'est chez l'épouse du député à la Constituante Duval d'Eprémesnil dont la société royaliste très fréquentée se tenait à Paris rue Bertin Poiré que se trama, en février 1791, une opération politique assez mal menée qui passa pour une tentative d'enlèvement de Louis XVI ${ }^{50}$. Née en 1749, à l'île Bourbon, Françoise-Augustine Sentuary avait d'abord épousé un avocat au Parlement de Bordeaux en premières noces (Thilorier, parent de l'avocat de Cagliostro) puis le conseiller au Parlement de Paris Duval d'Eprémesnil (1786) qu'elle soutint activement lors de la fronde parlementaire de 1788 qui avait entraîné l'arrestation de son mari. Condamné à la détention aux îles SainteMarguerite $^{51}$, il se posa en victime de l'arbitraire royal mais son opposition, essentiellement corporatiste, était celle des propriétaires terriens qui s'opposaient aux réformes fiscales préconisées par Loménie de Brienne. Bien que non noble, il avait été élu par faveur député de la noblesse aux États généraux, et devenu royaliste intransigeant, il contribua à la formation de réseaux contre-révolutionnaires. Mélomane comme toute sa famille, Mme d'Eprémesnil avait attiré chez elle des artistes et des musiciens (Steibelt, Ferrari, Herman, etc) mais son cercle était surtout composé de députés de la droite ultra. Parmi les habitués, on remarquait tous ceux qui manifestaient journellement à l'Assemblée leur hostilité aux libéraux de l'entourage des Lameth. Parmi eux, on remarquait le comte de Montlosier, les barons de Malouet et de Guilhermy, le vicomte de Bonneval, le marquis de Foucault, le bailli de Crussol, le cidevant marquis de Beauharnais, le député Cazalès, le vicomte de Ségur, Mirabeau le cadet, le baron de Batz qui épousa une fille de Mme d'Eprémesnil, également Mme de 
Grollier née Fuligny Damas ${ }^{52}$, tous aristocrates, tous engagés dans une stratégie de harcèlement procédural et de provocation visant à paralyser ou discréditer les travaux de l'Assemblée. Avec quelques-uns des 152 membres du club monarchique dont il était l'un des zélateurs actifs, d'Eprémesnil concerta un jour cette fameuse opération dite des « chevaliers » du poignard - ainsi nommés car ces conjurés étaient armés - dont le but inavoué était d'entraîner Louis XVI hors de Paris ${ }^{53}$. Plusieurs des habitués du cercle de Mme d'Eprémesnil dont sa sœur, Mme de Bonneuil, alors la maîtresse du député Cazalès, furent cités quelques semaines plus tard dans le procès-verbal d'une affaire assez curieuse où un certain nombre de femmes se trouvaient compromises. Le 18 avril 1791, une dénonciation avait été lancée au comité de la section du Roule, laissant supposer que les personnes réunies dans le grand salon d'apparat de l'hôtel d'Esclignac, rue du Faubourg Saint-Honoré, avaient formé le projet d'enlever Louis XVI sur la route de Saint-Cloud où il devait se rendre le jour de Pâques, pour ensuite l'escorter en Normandie. Lorsqu'ils sortirent dans la rue, encadrés de gardes, on vit que les hommes étaient armés et que les femmes étaient habillées en amazones. Ils étaient une cinquantaine dont, au comité de section, on se borna à relever les noms qui furent publiés $^{54}$.

D'autres cercles et sociétés royalistes comparables aux précédents continuèrent à œuvrer en liaison avec les Tuileries. Ainsi chez Mme de Montmorin Saint-Hérem, épouse du ministre des Affaires étrangères de ce nom, successeur de Vergennes. Son hôtel de la rue Plumet était fréquenté par des diplomates en poste à Paris et on y recevait un certain nombre d'écrivains propagandistes recrutés par le ministre luimême, et notamment les rédacteurs du journal royaliste les Actes des Apôtres ${ }^{55}$. Les Montmorin fréquentaient beaucoup Malesherbes et sa sœur, Mme de Sénozan, également les membres des familles de Brienne dont Mme de Canisy, et les Mégret d'Etigny qui avaient eux aussi des résidences en Haute-Marne ${ }^{56}$. Parmi les étrangers de marque on remarquait chez eux la comtesse d'Albany qui recevait elle-même une société très politisée ${ }^{57}$. L'une des filles des Montmorin, la ci-devant comtesse de Beaumont, connue plus tard pour ses relations avec Chateaubriand, chercha, dit-on, à attirer le député grenoblois Barnave et d'autres Feuillants dans les intérêts de la cour. C'était de fait le rôle de certaines de ces mondaines, rompues à l'art de la séduction et de l'intrigue, d'amener d'une manière ou d'une autre les hommes politiques qu'elles savaient populaires ou influents, élus, clubistes ou rédacteurs d'articles de journaux, à changer de cap $^{58}$. Depuis la mort de Mirabeau qui servait ses intérêts en sous main, la cour des Tuileries chercha plus que jamais à exercer des pressions variées auprès de certains députés et à intervenir dans l'équilibre des forces en présence au sein de l'Assemblée. Elle et d'autres femmes ont exercé une sorte de «lobbying ", multipliant les promesses en tout genre, pour convaincre des députés d'orienter les discussions des comités, notamment les Comités Diplomatique et de Liquidation. Plusieurs auteurs désargentés qu'elles contactaient et invitaient à des dîners acceptaient enfin d'être subventionnés, vendaient leur plume, et certains même étaient utilisés pour la propagande contre-révolutionnaire ${ }^{59}$. Il y eut même, semble-t-il, quelques tentatives pour s'attacher des femmes auteurs parmi lesquelles Mme de Gouges qui, dans son Compte moral de novembre 1792, raconte en détail les tentatives infructueuses qui furent tentées auprès d'elle par les dispensateurs de la Liste civile.

Un cercle constituant, le « salon » de Mme de Lameth

16 Les sociétés particulières du temps de la Constituante, aux nuances et couleurs politiques changeantes, étaient, au fil des événements qui se succédaient, abandonnées 
par leurs habitués mais en gagnaient de nouveaux, et il n'y avait rien d'étonnant à y croiser des personnages aussi politiquement dissemblables que sont apparus rétrospectivement Brissot, Mirabeau, Desmoulins, Laclos, Barère, La Fayette ou encore Tallien qui fut secrétaire de Charles de Lameth. L'épisode de Varennes - mais surtout la pétition de déchéance signée par les Parisiens au Champ-de-Mars ${ }^{60}$ - fut un des motifs principaux de la grande fracture au sein de la classe politique réformatrice et conséquemment au club des Jacobins qui se scinda. Le cercle aussi politique que policé de Mme de Lameth eut une certaine importance politique de 1789 à 1791 dans le prolongement du premier club des Jacobins. Après Varennes et la scission des Jacobins, il devint feuillant, perdant du même coup un certain nombre de ses habitués parmi lesquels Robespierre ${ }^{61}$. La maitresse de maison recevait tant au château d'Osny, près de Pontoise, qu'à Paris, dans l'hôtel particulier familial du Cul-de-sac Notre-Dame-desChamps, paroisse Saint-Sulpice ${ }^{62}$. Chez elle, on examinait les projets de loi, on envisageait des réponses à apporter aux objections des oppositions des "Noirs " l'abbé Maury, d'Eprémesnil, Cazalès, etc. - et des orléanistes puis républicains regroupés autour de Sillery, Brissot et Desmoulins. La fille des Lameth, future Mme Scipion de Nicolay, a raconté dans ses Souvenirs, avoir rencontré Robespierre nommé par les États d'Artois et qui venait régulièrement prendre des repas chez ses parents avec, raconte-t-elle, « ceux des députés du tiers état dont les ressources n'étaient pas assez considérables pour bien vivre à Paris $»^{63}$. Barnave, orateur en vue à la Constituante, co-fondateur avec les Lameth et Duport du club des Feuillants était fort en vue dans cette société politisée dont les piliers furent les libéraux Alexandre et Stanislas de Girardin, tous deux zélateurs de Rousseau, le général Mathieu Dumas, le colonel François de Jaucourt qui était accompagné de sa maîtresse l'ex-comtesse de Lachâtre ${ }^{64}$. Cette dernière est vivement prise à partie par le comte d'Espinchal dans son Journal d'émigration comme étant « une des plus zélées constitutionnelles de la capitale [...] Son boudoir, dit-il, est devenu le lieu de réunion de tous les agréables du parti démocratique parmi lesquels on distinguait principalement les Lameth, Barnave, le prince de Broglie, etc. Elle a été citée comme une des plus zélées patriotes. On l'a vue partout où elle a pu donner des preuves de son civisme. Elle a paru aux tribunes de l'assemblée, dans les jardins et promenades publiques, suivie d'une cour révolutionnaire. Elle s'est fait remarquer au Champ de Mars avec la princesse de Broglie et quelques autres de sa trempe lorsqu'il a été question d'y élever l'autel de la patrie pour la fédération du 14 juillet 1790. » Issue comme Mmes de Lameth ou de Fontenay, de la grande aristocratie financière, Mme de Lachâtre était petite-fille de Teyssier, l'homme d'affaires de Samuel Bernard et héritière de Beaujon. Elle était à la tête d'une grande fortune mise au service du parti libéral et les femmes qui, comme elle, avaient soutenu les premiers pas de la Révolution, étaient haïes par l'émigration dont d'Espinchal se fait l'écho ${ }^{65}$. Une autre femme, la ci-devant marquise de Coigny, bien que fille du maréchal de Conflans d'Armentières, appartenait à cette même société de libéraux, et fut rebaptisée la « reine de Paris » par d'Espinchal prompt à dénoncer les «traîtres » à leur caste d'origine ${ }^{66}$. Mme de Lameth était elle-même brocardée dans la presse royaliste, notamment le Journal de la Cour, sous le nom de « Dondon Picot » et on citait en mauvaise part, parmi les femmes qui l'accompagnaient aux séances de l'Assemblée, la duchesse d'Aiguillon dont le mari, honni des royalistes ${ }^{67}$ passait pour l'un des metteurs en œuvre de la journée du 6 octobre 1789, Mme de ClermontTonnerre, épouse d'un des présidents de l'Assemblée, Mme de Castellane et enfin Mme de Vin de Fontenay née Cabarrus, épouse d'un conseiller au parlement de Bordeaux, qui 
était une amie d'enfance de Mme de Lameth: "Elles étaient toutes les deux de Bayonne, raconte Mme de Nicolay, ce qui était la première cause de leur relation. Elle avait environ vingt ans et était d'une beauté remarquable : elle a été destinée à jouer un grand rôle auquel tout le monde a été initié ». "On ne peut, ajoute t-elle, lui refuser d'avoir rendu de grands services, sauvé des existences menacées, disposé souvent à l'indulgence l'inexplicable mari qu'elle avait choisi ${ }^{68}$.

Les cercles d'Auteuil

17 Les villages d'Auteuil et Passy, alors villégiature pour les Parisiens, furent des lieux à la mode où, sous la Révolution, se retrouvèrent beaucoup de politiciens, tels que Mirabeau ou Hébert qui fréquentait chez son ami le banquier Jean Conrad de Koch. Le village d'Auteuil garde surtout le souvenir du passage en 1792 et 1793 de Sophie de Grouchy, future Mme de Condorcet, personnalité originale et attachante qui subit l'influence des philosophes surtout à partir du moment où elle se fut provisoirement éloignée de sa famille. C'est paradoxalement dans un chapitre réservé aux jeunes filles nobles qu'elle découvrit les auteurs modernes et qu'elle s'éloigna définitivement de la religion catholique. Dès 1786, année de son mariage avec Marie-Jean Antoine Nicolas Caritat, marquis de Condorcet, elle manifesta ses idées de transformation du monde : à l'hôtel des Monnaies, quai Conti, elle forma un cercle ouvert aux littéraires et scientifiques français ou étrangers, également aux juristes dont le fameux Dupaty qui, entre autres causes célèbres, avait défendu trois innocents condamnés à la roue. Elle voulait forger les moyens d'assurer la tolérance en matière politique et religieuse, l'égalité des individus et des peuples, l'amélioration de la condition humaine et l'établissement d'une paix universelle. Dans cette démarche où elle s'inspirait des philosophes et des moralistes de l'époque, elle voulait favoriser la laïcisation des institutions et montrer qu'il n'existait d'autres vérités que celles reposant sur la science et la raison. "Sa conversation, dit Mme d'Abrantès, était quelquefois spirituelle et légère, mais le plus souvent abstraite et d'un sérieux qui excluait le charme et la causerie intime.» Chez elle, on croisait un certain nombre d'étrangers de marque dont Thomas Paine, héros de l'indépendance américaine, le futur président des États-Unis Jefferson, le neveu de Benjamin Franklin, Adam Smith, économiste distingué dont elle traduisit un traité, ou encore les voltairiens Villette - mari et femme -, Anacharsis Cloots qui collabora avec Condorcet au Journal de Paris et à la Chronique de Paris et de nombreux amis de la liberté qui contribuèrent à faire de ce «salon » un centre de l'Europe éclairée. À la fin de 1790, Mme de Condorcet s'installa avec les siens dans un hôtel particulier de la rue de Bourbon (actuelle rue Lille $\mathrm{n}^{\circ} 73$ ) y tenant un des premiers " foyers républicains ${ }^{69}$, ce qui lui valut de devenir la cible des journaux royalistes qui épiloguaient sur son égarement politique et ses amants, vrais et supposés. Un espion de Coblence, Jacquet de la Douay se fait l'écho de ces malveillances : «Mme de Condorcet, déclara-t-il en juin 1792 aux princes émigrés, avant son intrigue avec M. Depont ${ }^{70}$ vivait scandaleusement avec l'évêque d'Autun [sic] qui lui avait meublé une petite maison du côté de Mantes. Elle et Mme de Castellane sont de vrais piliers de la tribune du manège. Elles y donnent le ton des huées et des applaudissements, suivant le désir ou l'intérêt des Jacobins et, partout ailleurs, sonnent le tocsin contre ce qui reste de fantôme de l'autorité royale $[\ldots] »^{71}$

18 Des hommes nouveaux, membres de la Constituante et des divers clubs s'étaient joints aux habitués de son cénacle et on y retrouvait les habitués de sa voisine d'Auteuil, Mme Helvétius, à l'exception de Morellet et de quelques autres qui réprouvaient son engagement politique et se déplacèrent chez Mme de Pastoret, célèbre modèle du 
peintre David, qui présidait une assemblée à la fois libérale et aristocratique, dans un appartement somptueux situé à l'angle de l'ex-rue Royale et de la place de la Révolution, ex-Louis XV ${ }^{72}$. Choquée par la fusillade du 17 juillet 1791 dont elle avait été témoin, Mme de Condorcet manifesta dès lors publiquement son intérêt pour l'instauration d'une République en France. Membre de la municipalité parisienne en 1791 puis commissaire de la Trésorerie nationale, son mari fut peu après élu à l'Assemblée législative où il siégea parmi les députés républicains de la Gironde. Il s'adonna passionnément à ses fonctions et passa, aux yeux de l'émigration qui le détestait, pour un des inspirateurs de la journée du 10 Août. Ayant cependant voté contre la mort de Louis XVI, puis ayant publié un pamphlet intitulé Au citoyen français, sur la nouvelle constitution, il fut dénoncé par Chabot le 8 juillet et les scellés furent posés chez lui à Paris et à Auteuil où Mme de Condorcet s'était définitivement retirée dans sa maison de la Grande rue, $\mathrm{n}^{\circ} 2$, y recevant la même société que sa voisine Mme Helvétius.

19 Mme de Condorcet arrivait en terrain connu à Auteuil où logeaient deux de ses relations, Mme de Gouges $^{73}$ et Mme Helvétius qui, vers mars 1792, furent simultanément dénoncées dans un article haineux par l'abbé Bonnefoy de Bouyon, journaliste royaliste, auteur d'un périodique intitulé À deux liards mon journal. Il y traitait les deux femmes de «sorcières » tenant leur « sabbat » à Auteuil.

Haut lieu de la propagation des idées libérales, le domicile de la veuve du fermier général et philosophe Helvétius, auteur de L'Esprit, ouvrage philosophique brûlé en 1759, a probablement abrité le plus prestigieux des cercles intellectuels de l'époque. Issue de la haute noblesse lorraine, devenue veuve en 1771, cette dame s'était retirée dans une vaste demeure située Grande rue ( $\left.\mathrm{n}^{0} 24\right)$, agrémentée d'un beau jardin ${ }^{74}$. Elle y tint table ouverte pendant des années, recevant des personnalités en vue dont Turgot et Franklin. Après le 4 août 1789, Mme Helvétius récupéra une partie des habitués du "salon» de sa voisine, Mme de Boufflers ${ }^{75}$. Le culte rendu à Helvétius explique la ferveur qu'entourait celle qu'on baptisa bientôt Notre Dame d'Auteuil. Dans les années 1780 , cette maison accueillante fut en quelque sorte une annexe de la Loge maçonnique des Neuf-Sœurs : Jean-Jacques Le Français de Lalande, fils d'un directeur des postes et tabacs, élève des Jésuites à Lyon puis astronome réputé, l'avait co-fondée avec le chevalier Michel de Cubières et parmi ses membres on comptait Nicolas Dalleyrac, Chamfort, ou encore le vicomte de Noé, grand maître des cérémonies de cette loge artistique et littéraire. Cubières, dit Dorat-Cubières, y lut des extraits des discours de réception des nouveaux membres (cf. les Hochets de ma jeunesse, Paris, 1780). Mme Helvétius vouait une affection maternelle à Cabanis, jeune médecin qui vivait à demeure chez elle, s'affrontant régulièrement au poète Roucher sur les aspects démagogiques de la Révolution. Mme Helvétius reçut aussi Mirabeau et sa sœur Mme du Saillant, ou bien encore les Suard et les Condorcet, le réformiste Destutt de Tracy qui préférait une évolution raisonnable et pacifique à une révolution brutale et souvent sanglante, Volney connu pour ses récits de voyage, ou encore Daunou qui, diton, voua sa vie «à la vérité et à la raison " $^{76}$. Après le coup d'État de brumaire an VIII, plusieurs d'entre eux furent agrégés à la haute administration consulaire.

21 Les amis de Mme Helvétius se positionnaient de façon comparable sur les ordres du jour de l'Assemblée et ils avaient la même volonté que l'œuvre constitutionnelle fût achevée et la Révolution avec elle puisque, selon quelques-uns d'entre eux, l'essentiel avait été atteint dans la nuit du 4 août 1789. Quand Louis XVI fut mis en jugement, tous 
se montrèrent hostiles à sa mise à mort qu'ils jugeaient inutile. Les grands bourgeois intellectuels de cette société furent généralement poursuivis dès 1793 et ils se dispersèrent pendant la Terreur. Compatissante aux souffrances des vivants, Mme Helvétius « aurait, disait-on, désiré que des fleuves de bouillie circulassent partout afin que les hommes et les animaux trouvassent une nourriture facile et n'eussent plus rien à se disputer $"{ }^{77}$. Elle laissait dire, elle laissait passer les sophismes, les paradoxes, les systèmes sans trop les prendre au sérieux; ou bien elle les dégonflait par une saillie imprévue. Morellet rapporte qu'avec un esprit original et un naturel de répartie elle dérangeait fort les discussions philosophiques.

Les dernières sociétés aristocratiques

22 Après Varennes, le sort de la monarchie était suspendu à la déclaration de guerre, et encouragé par certains de ses ministres et conseillers occultes, Louis XVI se convainquit qu'une défaite militaire lui rendrait son pouvoir absolu. On l'escomptait en la préparant, tout d'abord sur le plan diplomatique - le cabinet des Tuileries menait une diplomatie parallèle indépendamment de l'Assemblée - et aussi en neutralisant l'organisation de la défense nationale : Louis XVI invita ainsi ses ministres de la Guerre (dont Narbonne, l'ami intime de Mme de Staël) et de la Marine à faire cesser les fabrications dans les arsenaux, et à encourager l'émigration des officiers et anciens cadres de l'armée, souvent des hommes expérimentés, en leur procurant des congés et des passeports. Entré au gouvernement le 6 décembre $1792^{78}$, Narbonne avait formé un cabinet composé de militaires à double visage comme le général d'Arblay son maitre de camp et, à la veille de la déclaration de guerre dont l'opportunité faisait l'objet d'affrontement à l'Assemblée, ce ministre soumissionnait avec des compagnies privées fort suspectes comme la compagnie Lanchères. Un nommé Jacquet de la Douay, espion des émigrés de Coblence, a détaillé les projets nébuleux de Narbonne et de son administration sur les fournitures de guerre et les chevaux de remonte qu'on s'apprêtait à livrer à l'ennemi, selon les instructions secrètes des Tuileries. Il parle aussi en mauvaise part de Mme de Staël qui animait une société politique et cosmopolite importante et disposait de moyens quasi illimités :

«Mme la baronne de Staël, écrit-il, pendant le ministère de M. de Narbonne, n'a cessé de fréquenter le château des Tuileries, où on la voyait avec étonnement dans les bonnes grâces de la reine, ainsi que Mme la duchesse de Luynes, les honnêtes gens sachant que ces deux femmes trahissaient sa Majesté. Les conciliabules de cette baronne surnommée la Mégère sont ordinairement composés des sieurs Condorcet et de sa femme, de l'évêque d'Autun, de Brissot, de Langlade, premier commis des Affaires étrangères, de Mme la vicomtesse de Laval-Boulogne, de plusieurs officiers suisses dont on a lieu de soupçonner la façon de penser, particulièrement M. d'Affry fils. On sait aussi certainement qu'un des projets de Mme de Staël était de faire rappeler $\mathrm{M}$. Necker son père. $»^{79}$

C'est sous le ministère Narbonne qu'eut lieu un projet contre-révolutionnaire que l'on connaît grâce aux minutes de procès de quelques-uns de ses protagonistes déférés au Tribunal révolutionnaire de 1794. Ceux-ci étaient d'anciens membres du Ministère de la Guerre, en particulier le comte de Saint-Paul, chef de bureau au ministère, son beaufrère par sa femme, Bourbotte dit Dussaulx, capitaine d'infanterie et pensionnaire du roi, et Delalain, premier commis au bureau de la guerre ${ }^{80}$. La sœur de Delalain, Mme de Navarre, qui était dame de compagnie de Madame Elisabeth aux Tuileries, assurait la liaison entre les conjurés et la famille royale ${ }^{81}$. Mais ce projet mal construit, au financement incertain fut, malgré l'insistance de Marie-Antoinette et de Madame Elisabeth, refusé par Louis XVI. Mme de Staël qui voyait journellement Narbonne et un 
certain nombre d'anciens ministres ou de députés feuillants était assurément initiée à leurs projets ${ }^{82}$. Privés de représentation parlementaire puisqu'ils ne pouvaient pas se représenter à la Législative, les anciens Constituants se regroupaient dans le cercle formé rue du Bac par Mme de Staël, et plusieurs d'entre eux, comme Malouet, furent initiés au secret des opérations de corruption financées sur les fonds de la Liste Civile.

Un nouveau projet d'évasion s'organisa après la journée du 20 juin 1792 qui avait effrayé Louis XVI. Mme de Staël y prêta son concours financier ${ }^{83}$ tandis que la conception générale en était confiée au duc de La Rochefoucauld-Liancourt qui avait, paraît-il, l'aval de Marie-Antoinette. Mmes de Laval ${ }^{84}$ et de Luynes, jusqu'alors détestées par la cour pour leur soutien à la majorité constituante de 1789 à 1791, secondèrent le projet de Liancourt et de Mme de Staël . Après les événements du 10 Août qui balaya les calculs politiciens et les chimères royalistes, Mme de Staël et sa coterie intervinrent efficacement pour sauver leurs amis, et notamment le comte François de Jaucourt (grâce à son intervention auprès de Manuel, procureur de la Commune) ${ }^{85}$. Cependant, plusieurs de ses habitués furent poursuivis, tels que Regnaud de Saint-Jean d'Angély, Adrien Duport ou Desmeuniers dont les noms figurèrent sur des listes de proscription qui circulèrent à la veille des massacres de septembre. Certains proscrits se retirèrent en Normandie, d'autres furent massacrés à Paris ou Versailles.

Dans les ultimes tentatives des royalistes pour éviter la déchéance de Louis XVI, on cite généralement le cercle politique formé au château des Tuileries et placé sous la présidence de la princesse de Lamballe revenue d'émigration. Une dénonciation émanant du comité de surveillance de la Législative, en mars 1792, signée par Carra, Chabot et Basire, alerta l'Assemblée législative sur les menées d'un "comité autrichien » des Tuileries, dans les appartements de la princesse de Lamballe qui y représentait Marie-Antoinette ${ }^{86}$. Ces réunions politiques auxquelles participaient d'anciens ministres - Montmorin, Bertrand de Molleville, Valdec de Lessart - et des personnalités comme Malouet ${ }^{87}$, le duc de Brissac et le baron de Gilliers, se déroulaient en concertation avec Louis XVI et Marie-Antoinette. À l'époque, l'affaire dite du Comité autrichien fut montée en épingle selon les uns ${ }^{88}$, habilement étouffée selon les autres ${ }^{89}$, et la princesse de Lamballe ne fut ni appelée à témoigner ni à se justifier d'accusations qui furent d'ailleurs niées en bloc par les royalistes. Les indices et même les preuves de l'activisme politique et de la duplicité de la cour et de son entourage, ne sont apparues que plus tard, lors de la découverte des papiers de «l'armoire de fer »-le coffre où Louis XVI dissimulait ses archives et sa correspondance - , ou bien encore dans les lettres originales saisies au cours des perquisitions qui eurent lieu chez des familiers des Tuileries au lendemain du 10 Août $^{90}$. Il y avait, entre autres, des instructions confiées par Louis XVI à des ministres comme Montmorin et Bertrand de Molleville, ou à d'anciens serviteurs de la cour comme Arnault de Laporte ou Thierry de Ville d'Avray. Mme Campan, lectrice de Marie-Antoinette, raconte elle-même avoir été dépositaire de papiers d'une haute importance pouvant être utilisés à charge contre Louis XVI et Marie-Antoinette ${ }^{91}$.

Non seulement ces documents établissaient la duplicité des souverains déchus mais ils étaient de nature à éclairer la complicité d'un certain nombre de personnages appartenant aux clubs, affichant une couleur ultra révolutionnaire, mais s'étant laissés soudoyer comme dans le cas du marchand de vin et clubiste en vue François Desfieux ${ }^{92}$. Parmi les personnes recherchées pour complicité avec la famille royale, après le 10 Août, figurait Mme de Grammont, née Béatrice de Choiseul-Stainville, sœur de l'ancien 
ministre Choiseul ${ }^{93}$. Depuis l'Ancien Régime, elle tenait un cercle politique très actif rue de la Grange Batelière $n^{\circ} 2$ - où elle servait la réputation et les intrigues du ministre Choiseul son frère. Son cercle se prolongea jusqu'en 1793 et Arnaud de Lestapis en a évoqué le fonctionnement sous la Révolution ${ }^{94}$. Les habitués étaient composés d'une partie des membres du "comité autrichien", auxquels s'adjoignirent un certain nombre de personnes comme la ci-devant comtesse d'Ossun, ancienne dame d'honneur, le comte de Thiars de Bissy, le duc et la duchesse du Châtelet, Roux de Puyvert, la famille de Damas, la princesse de Poix née Laborde ${ }^{95}$, M. de Choiseul-Labaume, SimonCharles Boutin, ancien trésorier de la Marine, M. Picquet du Boisguy etc., tous disposant de gros moyens financiers. Mme de Grammont, entre autres, entreprit de soudoyer certains membres de la Commune de Paris et notamment Sergent et son ami Panis, beau-frère de Santerre ${ }^{96}$, commandant de la garde nationale, lui aussi accessible aux pots-de-vin, pour permettre l'évasion de certains de ses amis en grand danger comme le ci-devant prince de Poix arrêté, qui échappa pour finir aux massacres de septembre. Mme de Grammont et quelques autres femmes sollicitèrent des autorités des signatures de complaisance apposées sur des certificats de résidence ou des passeports qui furent remis à ceux qui en avaient besoin. Il y eut d'ailleurs un véritable trafic de fausses griffes, des radiations spontanées de listes d'émigrés et, quelques mois plus tard, des pressions sur les membres du Comité de Sûreté générale, et même, semble-t-il, des interventions sur le cours des procédures au Tribunal révolutionnaire ${ }^{97}$. Secondant Mme de Grammont, on citera Mme de Laubespin qui avait des relations avec plusieurs membres du Comité de Sûreté générale de 1793, notamment Basire, Guffroy et Rovère, et auprès des membres du directoire du département de Paris où elle avait ses entrées ${ }^{98}$. Canal de la corruption organisée dans les milieux politiques, elle contribua à faire sortir de prison un certain nombre de personnes gravement compromises, comme la duchesse de Choiseul, en arrestation à Amiens, ou fit délivrer des certificats de complaisance (de non émigration ou de résidence) à des suspects comme M. de Béranger. Mme de Simiane, née Damas, elle, entretenait en 1792 et 1793 des relations intéressées avec Lulier, membre influent du Directoire du département de Paris, et avec certains ministres comme Garat, garde des Sceaux puis ministre de l'Intérieur à partir de mars 1793, à qui elle dictait certaines interventions en conseil des ministres ${ }^{99}$. Efficace, elle procura des certificats à ses amis suspects et notamment à son oncle, le duc du Châtelet, chef du réseau de corruption mis en place à Paris après l'exécution de Louis XVI. Jusqu'en décembre 1793, elle cherchera (pétition du 5 décembre 93) à protéger Du Châtelet qui fut exécuté. Emprisonnée en germinal an II, elle fut mise en liberté après Thermidor.

Les « salons » de la République

Outre les cercles formés chez Mme de Condorcet et Mme de Villette dont les époux furent membres de la Convention, plusieurs assemblées politiques et mondaines demeurèrent actives jusqu'en 1793. Parmi celles-ci, l'hôtel de Mme Julie Talma, ancienne danseuse dotée de grandes qualités intellectuelles ${ }^{100}$. "Melle Julie » comme on l'appelait n'était pas une courtisane ordinaire et son boudoir, très vite, s'était transformé en «bureau d'esprit ». Économe et astucieuse, elle plaça les fonds qu'elle avait retirés de la galanterie en se livrant à la spéculation immobilière dans le quartier de la Chaussée d'Antin, en liaison avec des architectes comme Brongniart et Ledoux. À la tête d'une petite fortune, elle épousa civilement le comédien Talma en juillet $1790^{101}$. Il envoya à ce sujet une adresse à l'Assemblée nationale représentant les difficultés opposées à son mariage par le curé de Saint-Sulpice qui exigeait de lui une renonciation 
à son état de comédien et invoquant les droits civils établis par la Constitution. Cette adresse fut renvoyée au Comité Ecclésiastique. Talma avait pris position dès 1789 pour le parti de la Révolution, créant une scission au sein de la Comédie-Française et entraînant après lui plusieurs comédiens démocrates parmi lesquels Monvel, Mme Vestris, Melle Candeille. «Le vicomte de Ségur qui l'aima s'était persuadé, écrit d'Espinchal, qu'elle serait la Ninon du XVIII e siècle, mais nul n'aurait pu prévoir que cette tendre et sensible courtisane serait une ardente révolutionnaire et deviendrait l'épouse de l'histrion Talma, Jacobin forcené et capitaine de garde nationale ${ }^{102}$. Pour Von Humboldt qui la rencontra, « Mme Talma possède manifestement plus d'esprit que les autres Françaises » et elle est "très patriotique ${ }^{103}$. L'affection de Talma pour sa femme ne dura que le temps de la Révolution, époque pendant laquelle celle-ci tint un cercle républicain à tendance girondine, situé rue Chantereine, $\mathrm{n}^{\circ}$ 61. Au mois de novembre 1792, au cours d'une soirée donnée en l'honneur de Dumouriez, Marat fit irruption chez les Talma avec plusieurs sans culottes, affectant de constater la présence en ces lieux de personnes ennemies de la Révolution. Il s'y trouvait essentiellement des Brissotins et des députés de la Gironde parmi lesquels Ducos et Vergniaud, et un certain nombre d'écrivains et d'acteurs, comme Melle Candeille et Mme de Gouges, tous admirateurs du général Dumouriez qui était alors salué en héros depuis la victoire de Valmy. Le lendemain, Marat publiait le récit circonstancié de cette visite dans L'Ami du Peuple, attirant l'attention des membres du club des Jacobins sur les « conciliabules » du salon Talma regardé comme repaire de contre-révolutionnaires. Julie Talma vécut séparée de son mari sous le Directoire, logeant rue de Matignon dans un petit hôtel qu'elle partageait avec Sophie de Condorcet qui fut une de ses plus proches amies. Talma demanda et obtint le divorce le 6 février 1801 afin de pouvoir épouser Caroline Vanhove, actrice elle-même divorcée depuis 1794. Quant à Mme Talma, elle conserva une petite cour d'admirateurs parmi lesquels Benjamin Constant qui demeura un ami dévoué ${ }^{104}$.

Autre cercle politique ou "salon » en vue au début de la première République, celui de Marie Jeanne, dite Manon, Phlipon, fille de graveur, connue sous le nom de son époux Jean-Marie Roland de la Platière, inspecteur général du commerce et des manufactures à Rouen et à Amiens. Elle tint un cercle politique, de la Constituante à la Convention, dans une grande maison de la rue Guénégaud, derrière l'Hôtel de la Monnaie. Elle prétendit n'en avoir assuré ni la direction ni l'animation mais il est difficile de la croire sur parole lorsqu'on sait la part non négligeable qu'elle prit dans la formation et la cohésion du groupe politique connu sous le nom de Girondins. Venue à Paris avec son mari en février 1791, elle avait aussitôt accueilli les amis politiques de son mari, exmembre de la municipalité de Lyon. On croisait chez elle plusieurs députés de la région de Bordeaux tels que Ducos, Fonfrède, Buzot, Guadet, Vergniaud, Gensonné. S'y pressaient encore le maire Pétion, Barbaroux, Bancal des Issarts, Brissot - avec lequel Mme Roland eut une correspondance -, Grégoire, Desmoulins et Robespierre. Tous ces hommes fameux furent les hôtes de Mme Roland. Mme de Condorcet, Miss Helena Williams et Mme Robert-Kéralio assistèrent vers 1791 à ces réunions, mais il est probable que les femmes étaient peu nombreuses si on juge par les positions assez conventionnelles de la maitresse de maison sur la distribution des rôles politiques entre hommes et femmes. Après l'arrestation de Louis XVI à Varennes, Mme Roland contribua à la fondation du journal le Républicain, et lorsque son mari fut nommé ministre, on dit qu'elle l'influença, chose vraisemblable. On dit en particulier qu'elle rédigea elle-même la lettre de Roland au roi, lettre dans laquelle, au lendemain de sa 
révocation, il le mettait en défiance. Cette lettre imprimée et envoyée à tous les départements eut un certain retentissement politique et préluda semble-t-il aux événements du 10 Août. Lors de l'affrontement avec les députés montagnards, au cours de l'automne 1792, Mme Roland passa pour l'âme du groupe des Girondins, et c'est véritablement à ce titre qu'elle fut arrêtée au lendemain du 2 juin 1793. Pétrie de culture classique, attachée aux grands principes, n'ayant aucune expérience des affaires - son mari ne fut ministre que quelques mois en 1792 -, elle tirait l'essentiel de sa culture politique de la lecture des Anciens. Son enthousiasme, voire son exaltation, ses positions comme ses jugements péremptoires qui ponctuent l'édition des Mémoires qu'on lui attribue, dénotent chez elle de la confusion, à tout le moins un certain manque de lucidité. Les échecs du parti girondin ne tiennent pas à son influence comme on a pu l'écrire après coup, et dire qu'elle a été néfaste au projet fédéraliste est évidemment excessif. Il reste qu'elle est, à cette époque, un personnage remarquable et Mallet du Pan, qui combattit ses principes, a dit à son sujet : « Elle méritait le cloître ou une principauté. »

Si on s'appuie sur une documentation diversifiée qui ne se limite pas aux archives parlementaires, aussi précieuses soient elles, on constate que les preneurs de décision comme les meneurs d'opinion, à quelque bord qu'ils appartinssent, étaient associés, inspirés voire influencés par les femmes des cercles qu'ils fréquentaient. Si certaines d'entre elles prirent la parole d'elles mêmes, comme Mme de Gouges, à travers des écrits publiés dans de mauvaises conditions, souvent mal diffusés, d'autres encore appartenant à différents courants politiques, qu'ils soient ou non représentés à l'Assemblée - ont décidé, dirigé, secondé des opérations d'opposition politique, souvent dans la clandestinité, de la fin de l'Ancien Régime à la Restauration. L'activité voire l'activisme politique des femmes, durant cette période, est toute entière avérée, établie dans l'instruction des enquêtes de police, dans les correspondances diplomatiques et dans les minutes de procès des tribunaux politiques ou d'exception. La reconnaissance de la "participation» des femmes dans les affaires politiques, particulièrement soulignée au Tribunal révolutionnaire et par Chaumette dans sa célèbre envolée à l'adresse des républicaines, a assez peu été prise en compte par les historiographies des divers bords politiques. Elles n'y ont vu que des femmes de la noblesse et des religieuses, coupables ou victimes selon les points de vue. Or contrairement à une idée reçue, les guillotinées de l'an II étaient aussi bien monarchistes que constitutionnelles et républicaines comme l'ont été Mme de Gouges et Mme Roland. Il y eut de toute façon une proportion notable de femmes libérales, ayant à cœur l'idéal démocratique de 1789 contenu dans la Déclaration des droits de l'homme. Mme de Gouges y fait clairement allusion dans la dernière affiche qu'elle ait publiée, depuis la prison de l'Abbaye, sous le titre Une patriote persécutée ${ }^{105}$. Une des plus représentatives de ces femmes persécutées a été Mme Desmoulins, née Lucile Duplessis-Laridon, qui n'était ni noble ni aristocrate ${ }^{106}$, pas plus que Mme Hébert, née Marguerite-Françoise Goupil, et d'autres moins connues, qui ont payé un lourd tribut à l'engagement qui fut le leur. Toutes ces démocrates, au sens large, qui se disent volontiers patriotes, y compris les habituées des cercles de Mmes Talma, de Condorcet et autres femmes que nous n'avons pas citées dans le cadre de cet article, eurent souvent, pour tort, au temps de la Terreur, de réclamer une République à visage humain. Il n'est pas inutile de reconsidérer la chronique révolutionnaire en distinguant de façon plus pertinente le rôle des femmes dans les coteries et factions, aussi bien les constitutionnelles que les royalistes, les jacobines et les feuillantines de 1791, les femmes de la mouvance girondine ou celles qui se 
partagèrent entre les courants incarnés par les factions de l'an II. La documentation qui permet d'affiner cette évaluation est, actuellement, insuffisamment exploitée, que ce soit les actes des assemblées élues, les documents de police émanant des divers comités de surveillance et de répression, également la presse dont le Thermomètre du Jour de Dulaure, le Journal des 83 départements de Gorsas ou la Chronique de Paris, rares journaux où des femmes connues ou inconnues ont pu s'exprimer, sans oublier les écrits et discours de femmes tirés à un nombre infimes d'exemplaires, quelquefois des placards in folio qui nous sont arrivés en exemplaires uniques comme certaines affiches du fonds Portiez de l'Oise. Les différents comités de surveillance politique de 1789 à 1792 et le Tribunal extraordinaire révolutionnaire de l'an II qui se sont indifféremment appuyés sur cette documentation pléthorique pour rédiger leurs réquisitoires ont, pour ce qui les concerne, établi, reconnu et sanctionné l'engagement politique de ces femmes ${ }^{107}$.

\section{NOTES}

1.Les académies littéraires d'Arras, de Lyon ou de Besançon et l'Académie royale de peinture et de sculpture, en leur ouvrant plus largement leurs portes dans le dernier quart du XVIII siècle, illustrent ce début de reconnaissance de leurs talents littéraires et artistiques.

2.Voir principalement les dossiers de la police politique de la Constituante à la Restauration, et principalement les sous-séries AB XIX, F7 et BB3 des Archives nationales.

3.Il est étrange que les pionnières de la libre parole du temps de la Révolution, comme le fut Théroigne de Méricourt, soient " psychiatrisées " par des auteurs médiatisés qui ont en commun une grande méconnaissance du contexte historique et multiplient les anachronismes comme on le constate avec effarement dans l'ouvrage d'Elisabeth Roudinesco et quelques autres du même genre. Anne Terwagne, de Marcourt en Belgique, disposait d'une coquette fortune lorsqu'elle fut arrêtée comme suspecte en juin 1794, transférée plus tard à la Salpêtrière et dépouillée par son frère Pierre Terwagne, ami et élève de David, qui la fit maintenir en détention forcée. Le seul travail de référence la concernant est l'ouvrage de Helga GRUBITzsCH et Roswitha BocKHolT, Théroigne de Méricourt, l'amazone de la Liberté, Pfaffenweiler, Centaurus, 1991.

4. Le mot est utilisé pour désigner les expositions de peinture de l'académie royale, de la jeunesse ou de la correspondance etc. On trouve aussi un Salon des arts - club réunissant des amateurs de peinture dans les galeries du Palais Royal - ou le « Salon Français » qui n'était pas un cercle mondain comme le suppose Antoine LiLTI, Le monde des salons. Sociabilité et mondanité à Paris au XVIII siècle, Fayard, 2005, mais un club d'activistes contre-révolutionnaires. Encore aujourd'hui, le mot « salon » s'entend au sens de raffinement de l'esprit, feu d'artifice verbal, réputations et élégances en tout genre. Il ignore la dimension politique et libertine, voire révolutionnaire de ces lieux qui a été évacuée par le XIX ${ }^{\mathrm{e}}$ siècle comme étant incompatible avec son incontournable représentation féminine. Nous avons donc utilisé avec prudence le mot « salon » qui a 
acquis, jusqu'à aujourd'hui, un sens restrictif, bien éloigné de la réalité du XVIII ${ }^{\mathrm{e}}$ siècle que nous connaissons.

5.La place des femmes dans la société avait changé on le sait : « Les femmes régnaient alors, écrit Mme Vigée-Lebrun, la Révolution les a détrônées ». Les mœurs « bourgeoises », de la Monarchie de Juillet à la troisième République, ont développé une amnésie généralisée concernant la visibilité du libertinage dans la société aristocratique de la fin du règne de Louis XVI. Sous Napoléon III, la censure du roman les Liaisons dangereuses de Choderlos de Laclos qui s'est complètement inspiré, pour ses personnages, du milieu qu'il fréquentait (en dépit de ce qu'affirme ingénument Antoine Lilti , op. cit.), en est une magnifique illustration.

6.Antoine LILTI, op. cit.

7.Wilhelm Von HumboLDT, Journal parisien (1797-1799), traduit de l'allemand par Elisabeth BEYER, préface d'Alberto MANGUEL, Solin/Actes Sud, 2001.

8.Certains auteurs omettent d'étudier le rôle crucial des cercles et sociétés politiques de la période Révolution-Empire, souvent dans leur rôle d'opposition aux gouvernements en place, ainsi Steven KALE, dans son essai intitulé French Salons, High Society and Political Sociability from the Old Regime to the Revolution of 1848, Baltimore and London, The Johns Hopkins University Press, 2005. Sur Mme Regnaud, voir Olivier BLANC, L'éminence grise de l'Empereur, Regnaud de Saint-Jean d'Angély, Paris, 2003.

9.Mémoire présenté au roi par SAS Mrg le duc d'Orléans, suivi de Lettre de M. de Crosne au Club du Palais-Royal, et Remontrances du Club au Baron (de Breteuil), et Lettre écrite au même par SAS le duc d'Orléans, Liège, 1787.

10.On y fonda le journal le Cosmopolite dirigé par Proly et Régnier. Melle de Champgrand qui épousa en premières noces le comte de Rohan Rochefort guillotiné en juin 1794 puis le comte de Saint-Simon, y fait allusion dans ses « Souvenirs " publiés sous le nom de baronne de Bawr, du nom de son troisième mari. Champgrand louait le rez-de-chaussée de son immeuble au glacier Corrazza où venaient les membres du club des Cordeliers. 11.Papiers Sholtho-Douglas, rapport sur les salons de jeu, W251, Dénonciation faite au public sur les dangers du jeu, Paris 1791.

12.Sur ces cercles, sociétés et académies, voir Olivier BLANC, Les Libertines, plaisir et liberté au temps des Lumières, Paris, Perrin, 1987 et L'Amour à Paris au temps de Louis XVI, Paris, Perrin, 2002.

13.La « famille Doublet de Persan » fut, confirme W. Von Humboldt, « la vraie source de toutes les nouvelles à la main » (op. cit., p. 326). Connues sous le nom de Mémoires secrets, ces nouvelles attribuées à Bachaumont qui n'en fut qu'un des rédacteurs, forment une documentation extraordinaire et indispensable à la connaissance de la société du XVIII ${ }^{e}$ siècle. Ce n'est pas un recueil de ragots sans importance, comme le croit Antoine LiLTI, op. cit., p. 345, mais une source d'informations précieuses maintes fois confirmées par les documents d'archives, et notamment les papiers des notaires qui, par exemple, enregistraient des donations entre amants.

14.AN, F7 4590, papiers Basire (1790).

15.Beaucoup cessèrent en août-septembre 1792 pour reprendre dès octobre suivant jusqu'à l'été 1793 où les dénonciations commencèrent à viser certains d'entre eux, ainsi celui de Mme de Bonneuil qui donnait bal à chaque revers des armées républicaines (AN, BB3 68 (148), celui de Mme Hosten rue Saint Georges, de Marie de Grandmaison à l'Ermitage de Bagnolet, ou des demoiselles d'Estat, amies du fournisseur agioteur d'Espagnac. 
16.Après la loi des suspects (17 septembre 1793) et l'interdiction faite aux femmes d'organiser des réunions et cercles (12 brumaire an II), la plupart des « salons » cessèrent apparemment d'exister (certains pourtant, bénéficiant de la protection de conventionnels - ceux de Mmes Simons, née Thierry, Robineau de Beaunoir, Demailly ou Saint Brice née d'Anneville -, continuèrent néanmoins d'exister). Ils reprirent tous dès la réaction thermidorienne (du 9 thermidor an II à vendémiaire an III) ; selon W. Von Humboldt qui écrit dans son journal parisien : «Sous la Terreur les femmes n'ont eu d'influence que sur les affaires particulières, point sur les publiques. Mais toute grâce passait par elles et quelques unes donnaient des réceptions où le commerce allait bon train. En revanche, du 9 thermidor au 13 vendémiaire, la réaction fut principalement organisée par les femmes et elles n'admirent personne qui eut pu être républicain, fût-ce en apparence » (p. 165).

17.Livre rouge, ou Liste des pensions secrètes sur le Trésor public, contenant les noms et qualités des pensionnaires, Paris, 1790 (attribué à l'abbé de La Reynie).

18.Après la prise de la Bastille, la duchesse de Polignac émigra en Italie puis s'installa avec son mari à Vienne où elle mourut en 1793. Voir les Lettres de Calonne à Mme de Polignac, Guillaume-Honoré Rocques de MONTGAILLARD (1772-1825), Histoire de la Révolution, I., p. 352 et II., p. 216, 281.

19.Voir à son sujet le Journal de Marc, marquis de Bombelles (1744-1822), pour 1784-1789.

20.Citée dans les enquêtes du Comité des recherches de la Constituante. Elle se désigna d'elle même en 1791 comme otage de Marie Antoinette. On la retrouve plus tard dans les dossiers de la police du Consulat, recherchée dans la région d'Altona pour son activisme anti-bonapartiste.

21. Arrêtée en juin 1791 comme complice de l'évasion de la famille royale. Exécutée en l'an II.

22.Sur le salon de Mme Necker, voir Actes du Congrès de littérature comparée, Dijon, 1960, p. 121-129.

23.Sur les cercles et salons de la fin de l'Ancien Régime et du début de la Révolution, une source importante est constituée par les Lettres de l'abbé Morellet publiées et annotées par Dorothy MEDLIN et Jean-Claude DAVID (eds.), Oxford, the Voltaire Foundation, 1991-1996 (3 volumes).

24.Transformé en pensionnat de luxe à usage des enfants du duc d'Orléans, des siens propres, et de ceux qu'ils avaient eu ensemble.

25.Jean HARMAND, Madame de Genlis, sa vie intime et politique, Paris, Perrin, 1912, p. 222.

26.Les enfants du duc d'Orléans, principalement le futur Louis-Philippe qui fut membre des Jacobins.

27.Mme de Genlis erra dans différentes villes avant de se fixer quelques années à Hambourg. En France sous le Consulat, elle fut pensionnée par Napoléon qui lui confia un rôle d'informatrice de salon. Ses contes, romans, concernent presque tous l'éducation et prônent des vertus dont l'auteur s'était naturellement détournée dans le monde où elle avait vécu. En 1825, ses Mémoires dans lesquels elle revisite allègrement son passé et celui des autres qu'elle cite souvent en mauvaise part, firent scandale. Elle mourut en 1830 .

28.Gilbert STENGER (1836-1913), «Le salon de Mme de Montesson », Nouvelle Revue, 18, 1902 , p. 252-263.

29. Olivier Blanc, Marie-Olympe de Gouges, une humaniste à la fin du XVIII ${ }^{e}$ siècle, Paris, René Viénet, 2003. 
30.Mme de Montalembert née Comarieu, fille d'un Inspecteur général des Domaines, organisa sa vie autour de son petit théâtre de la rue de la Roquette, $\mathrm{n}^{\circ} 39$; elle entretint des relations amicales avec le chevalier de Saint-Georges.

31.Mme Baconnières de Salverte, née Deslacs d'Arcombal, auteur de Pauline, pièce qu'elle monta rue des Amandiers Saint-Antoine, sur son petit théâtre de société.

32. Claire Silva veuve du comte de Maleyssie, capitaine aux gardes françaises, amie de l'auteur Sedaine qu'elle recevait chez elle à Saint Prix et rue de Bourbon (rue de Lille) où on jouait sur son théâtre de société des pièces refusées à la Comédie-Française. Elle épousa en secondes noces le comte de Lachabeaussière, fils d'un avocat au Parlement, garde du corps du comte d'Artois, qui quitta le service pour se consacrer à la littérature. La fille du premier mariage de Mme de Lachabeaussière épousa le comte Grimoard du Roure, ami d'Hébert, membre influent du club des Cordeliers qui se vengea sous la Terreur d'une accusation de Lachabeaussière parue dans le Journal de la loi du 1er août 1793.

33.Armand d'Allonville, Mémoires secrets, de 1770 à 1830, Paris, 1838, II, p. 192.

34.Née à Paris en 1738, fille d'un receveur général des Finances de Champagne, elle avait épousé en mars 1753 le comte Claude de Beauharnais et des Roches-Baritaud - né à Rochefort le 16 janvier 1717, chef d'escadre des armées navales, et mort le 25 décembre 1784 -, qui était l'oncle d'Alexandre de Beauharnais, le premier mari de Joséphine Tascher de la Pagerie, la future impératrice Joséphine.

35.Daniel HAMiche, La bataille de Charles IX, Paris, collection 10-18, 1967.

36. Michel de Cubières composa une Epître à Marie-Olympe de Gouges qui fut lue au PalaisÉgalité en juillet 1792.

37.Sous l'Empire, la comtesse de Beauharnais eut une position assez en vue par sa parenté avec l'impératrice Joséphine et elle mourut le 2 juillet 1813 à Paris. Le diplomate américain Gouverneur Morris, fort misogyne et fort amateur de femmes, se vantant d'avoir vaincu les résistances de Mme de Flahaut à la date du 14 juillet 1789, tourne en ridicule Mme de Beauharnais et son cercle.

38. Voir Jean STERn, Belle et bonne, une fervente amie de Voltaire[...], Paris, Hachette, 1938. 39.La sensibilité politique du couple de Villette ressort dans un ouvrage paru en 1792 à Paris chez Clousier, imprimeur de la Sorbonne, sous le titre de Lettres choisies de Charles Villette sur les principaux événements de la Révolution.

40.Sur la famille Abeille originaire de La Ciotat, voir les travaux de Georges LADEVIE, Généalogie et Histoire de la Caraibe (GHC), bulletin, n²0, octobre 1990, p. 210 et Héraldique et généalogie, sept.-oct. 1984.

41.L'esprit des Journaux français et étrangers, VI, juin 1787, p. 299.

42.Le conventionnel François Robert (1763-1820), originaire de la province de Namur, établi à Givet, enseigna le droit à Paris et eut aussi un commerce d'épiceries et de denrées coloniales. Le salon de Louise de Kéralio se tint 2, rue des Marais, Bulletin de la Société historique de Paris et de l'Ille-de-France, année 1960, p. 163-237.

43.Voir Christine FAURÉ, « Une histoire des femmes au $18^{\mathrm{e}}$ siècle. Louise de Kéralio », Revue de la BNF, $\mathrm{n}^{\circ} 17,2004$, p. 61.

44.Louise Robert à M. Louvet, député à la Convention..., Baudouin, 1793, 8 4 p.

45.AN, F7 3688/3. Il s'agit peut être d'une suite de l'observateur français ou le publiciste véridique et impartial commencé en 1791. Plusieurs membres de la famille Kéralio furent arrêtés et risquèrent l'échafaud. Mme Robert mourut à Bruxelles en 1821. 
46.Le plus grand nombre de départs en émigration n'eut pas lieu en 1789 mais plutôt en 1791 et 1792, et, avec la loi sur le divorce, beaucoup de femmes royalistes crurent pouvoir rester en France sans danger pour éviter le séquestre des biens familiaux. 47.Plusieurs furent envoyées à Sainte Pélagie, d'autres exilées à l'étranger ou en province comme Mmes de Damas et de Champcenetz. Il y eut très peu d'exécutions de femmes royalistes sous le Consulat et l'Empire.

48.Pierre CAILLET, Comité des recherches de l'Assemblée nationale..., Paris, 1993, 32, dossier 335, p. 13 à 17. Adolphe Mathurin de LESCURE (1833-1892), Correspondance secrète inédite sur Louis XVI, Marie-Antoinette, la cour et la ville de 1777 à 1792, Paris, Plon, 1866, II, p. 437. 49.Pierre CAILLET, op. cit., 15, dos. 64, p. 1 à 5. De LESCURE, op. cit., II, 476. Constance Louise d'Aumont, née en 1731, avait des possessions en Normandie dans la région de Rouen où elle résidait lorsqu'elle fut appelée à témoigner dans la procédure engagée par le Châtelet de Paris sur les événements du 6 octobre 1789. Elle dit avoir passé la nuit à Versailles en y assistant à des « horreurs".

50. Alexandre TUETEY (1842-1918), Répertoire général des sources manuscrites de l'histoire de Paris pendant la Révolution..., vol. II, 1890-1914.

51.Mme d'Eprémesnil avait elle même été menacée d'une lettre de cachet, voir Olivier BLANC, Les Libertines, op. cit., chapitre sur Mme d'Eprémesnil, p. 89-104.

52.Peintre de fleurs, amie de Mme Vigée-Lebrun, Mme de Grollier fut citée avec l'exbailli de Crussol dans l'instruction de l'affaire Cadoudal et les conspirations anglaises où de nombreux royalistes étaient compromis.

53.Le 28 février 1791, profitant d'une diversion à Vincennes où la garde nationale était accourue, ils étaient entrés en force aux Tuileries sous le prétexte que les jours du roi étaient en danger, mais celui-ci avait refusé de les suivre. Compromis dans diverses intrigues politiques, dénoncés dans les journaux de Camille Desmoulins (affaire de la Scioto Land Company) ou de Gorsas, d'Eprémesnil et son épouse furent exécutés en 1794. 54.Archives de la Préfecture de police, A/a section du Roule, 18 avril 1791. Complot manqué des aristocrates réunis sous le prétexte d'un concert à l'hôtel d'Esclignac, pour enlever le roi dans la nuit du 18 avril 1791, Paris (1791).

55.L'ancien ministre Montmorin fut massacré en septembre 1792.

56. En 1794, les habitués des châteaux de Brienne et de Passy sur Marne, dont Mme de Montmorin et ses enfants, furent tous arrêtés et la plupart exécutés

57.Née princesse de Stolberg-Redern, elle épousa le dernier Stuart, Charles-Edouard, petit-fils de Jacques II, qui prit le nom de comte d'Albany. Liée avec le poète Alfieri la comtesse d'Albany vint s'installer à Paris 24, rue de Provence, dans l'ancien hôtel Thélusson loué 20000 livres en 1788, y recevant un certain nombre d'étrangers, principalement Gouverneur Morris ambassadeur des États-Unis d'Amérique qui dans son Journal évoque l'ambiance « aristocratique et cosmopolite » des réceptions de la comtesse d'Albany.

58. Ernest d'HAUTERIVE, Journal d'émigration du comte d'Espinchal, Paris, 1912, p. 160. Pauline Marie Michèle Frédérique Ulrique de Montmorin avait épousé Christophe François de Beaumont.

59. À ce sujet, voir les Mémoires particuliers pour servir à l'histoire de la fin du règne de Louis XVI d'Antoine-François Bertrand de Molleville, Paris, L. G. Michaud, 1816.

60.La fusillade du 17 juillet qui radicalisa la Révolution a été fixée par un poignant dessin de David. Contrairement à ce que suggère Mona Ozouf dans Varennes - la mort de la Royauté, 21 juin 1791, Gallimard, 2005, l'événement sanglant du Champ-de-Mars fut le 
tournant de l'histoire de la Révolution et peut être envisagé comme une «journée historique ».

61.Comme plusieurs des habitués de ce salon Robespierre se fit faire le portrait par Mme Labille Guiard qui était elle-même reçue chez les Lameth.

62.Fille de Jean-Baptiste de Picot, marquis de Clermont en Agenois, ancien major commandant en l'Ile et Côte Saint Domingue et d'une mère créole propriétaire d'immenses plantations au sud de l'île d'Haïti, Mme de Lameth disposait d'une fortune considérable en biens assis à Bayonne et aux environs, cousinant avec la haute finance basque en particulier Laborde, Nogué, et Cabarrus. En plus de ses biens de famille, elle avait obtenu en 1782 une pension sur le Trésor royal s'élevant à 20000 livres. En 1784, elle avait épousé le comte Charles-Malo-François de Lameth d'une famille de Picardie, gentilhomme du comte d'Artois et «mestre de camp en second » du Régiment d'Orléans dragons. Frère de Théodore et cousin d'Alexandre de Lameth, Lameth avait pris part à la guerre de l'Indépendance des Etats-Unis sous Rochambeau en qualité de capitaine puis d'aide maréchal des Logis de l'armée. Élu député de la noblesse aux États généraux, il combattit les privilèges de la royauté et avec Talleyrand, il a été un des artisans du 4 Août.

63.Sur Mme de Lameth, voir Mémoires de la Société historique et archéologique de Pontoise et du Vexin, tome 40, 1930, p. 97-106. Également le Mercure de France, année 1939.

64. Marie Charlotte Louise Perrette Aglaé Bontems (1762-1848), épouse en 1778 de Claude-Louis de La Châtre, comte de Nançay, premier gentilhomme de la Chambre de Monsieur, était en rupture d'idée avec son mari qui émigra. Imprudemment revenue en France après la mort de Louis XVI, elle dut la vie à la protection du représentant en mission Dumont qui s'en expliqua dans ses justifications. Elle réussit enfin à passer en Suisse où l'attendait Jaucourt lui même rescapé des massacres de septembre puis émigré grâce à Mme de Staël : Voir Correspondance générale, présentée par Béatrice JASINSKI, tome III première partie, Pauvert, 1968, p. 30-31, 57, etc.

65.Ernest d'HAUTERIVE, Journal d'émigration du comte d'Espinchal, op. cit., p. 147, 160, 279. 66.Louise-Marthe de Conflans d'Armentières épousa François, marquis de Coigny (1756-1816), vétéran de la guerre d'Amérique, maréchal de camp en 1788 puis lieutenant général sous la Restauration. On fit courir le bruit qu'elle avait été fouettée par le peuple devant le château des Tuileries.

67.Ernest d'HAUTERIVE, op. cit., p. 149.

68.Le 25 pluviôse an II, Mme de Lameth qui avait refusé d'émigrer pour empêcher la confiscation de son patrimoine considérable, fut arrêtée avec son amie d'Aiguillon et elles partagèrent aux Carmes, la cellule de Mme de Beauharnais et de Mme de Custine. Leur amie Mme de Fontenay, future Tallien, fut arrêtée à son tour.

69. Rue de Bourbon $n^{\circ}$ 50. Gilbert STENGER, «La société et les amis de la marquise de Condorcet », Nouvelle Revue, t. 29, 1904, p. 196-210.

70.Lire de Pons, fils d'un intendant de Metz. Femme libre, Mme de Condorcet dissimula peu ses passions successives pour le « héros » La Fayette, pour Achille du Châtelet et plus tard Mailla Garat.

71.Correspondance de Berne, déclaration faite par le Sieur Jacquet de la Douay [...] le dimanche 24 juin 1792 dans la ville Luxembourg [...] par ordre du général Schroeder. Voir François Descostes, Joseph de Maistre pendant la Révolution, le marquis de Sales et les émigrés, 1789-1797, Tours, 1895.

72.Adelaïde Louise Piscatory avait épousé le 14 juillet 1789 Claude Emmanuel Pastoret Maître des Requêtes puis procureur général syndic du département de la Seine. Son 
mari siégea aux côtés des Girondins à l'Assemblée législative où il brilla par son modérantisme. Morellet parle des habitués de ce salon : Jean de Vaisnes et son fils Eusèbe, Louis Claude Chéron, Melle de Belz, les membres de la famille Thomas de Pange, les Trudaine, André Chénier, Mme Chalgrin, Piscatory, Melle Lucrèce d'Estat. Voir Dorothy MEDLIN, Jean-Claude DAVID et Paul LECLERC, Lettres d'André Morellet, Oxford, 1991-1996, vol.2 (index).

73.En 1790, elle emménagea rue du Buis $n^{\circ} 16$ (actuel n 4) et résilia son bail en 1793 pour s'installer au clos Figuier à Saint-Étienne de Chigny près de Tours.

74. Cette maison qu'elle avait acquise du peintre La Tour, fut détruite en 1871.

75.Marie-Charlotte-Hippolyte de Campet de Saujon, veuve en 1794 du comte Édouard de Boufflers-Rouverel (né en 1722). Connue sous le sobriquet de l'Idole du Temple (allusion au palais du Temple) par sa liaison avec le prince de Conti, qui occupa cette résidence jusqu'à sa mort en 1776.

76.Née Marie Anne de Ligniville nièce de Mme de Graffigny et parente de Choiseul. 77.Pierre-René AuguIs (1786-1846), Les Révélations indiscrètes du XVIII siècle, Paris, 1814. 78.Louis de Narbonne, né en 1755, mort à Torgau en 1813, ami de Talleyrand et Choiseul-Gouffier, accompagna Mesdames tantes à Rome en février 1791, revint à Paris et fut nommé ministre. Après le 10 Août il trouva un abri provisoire chez Mme de Staël puis émigra grâce à elle.

79. Correspondance de Berne, op. cit., p. 109.

80.Il écrivit à Brissac au sujet de son projet (22 mai 1792) assurant avoir 200 hommes à sa dévotion dont Delalain, Lanchères, Marcenay et son épouse fille de M. Herbert fermier des messageries.

81.Mmes de Navarre et Thibault née Noll, au service de Marie-Antoinette, ont secondé la tentative d'évasion de février 1793 conçue par Jarjayes et son épouse, née Marguerite Quetpée de Laborde, ancienne première femme de chambre. «Ces deux personnages, écrit Héron au sujet de Mme de Navarre et de son frère Delalain, ont toujours été les plus contre-révolutionnaires qu'on ait jamais vus. Ils tenaient des conciliabules et distribuaient 60000 croix de Saint-Louis pour lever des fonds destinés à la contrerévolution ». Mme Thibault « toujours dans les conspirations de la ci devant cour », fut citée dans la procédure du 6 octobre 1789 (F7 4774/28, liasse 3).

82.Ernest d'HAUTERIVE, Journal d'émigration du comte d'Espinchal, op. cit.

83.AN, 03/2620 et 2625 (des fonds considérables furent avancés par du Châtelet, d'Arlincourt, Bertrand de Molleville, Liancourt etc.)

84.D'Antraigues reprochait à Mme de Laval née Tavernier de Boulogne, d'avoir cherché à rapprocher la reine des Constituants : « La reine acceptant tout et proposant même au-delà des demandes, la duchesse de Luynes et la putain de vicomtesse de Laval, maîtresse de l'évêque d'Autun, sont ses intimes, et par ce moyen (assure) la correspondance avec Barnave, Lameth, Siéyès et d'autres du même genre ». Voir Jacqueline ChAuмIÉ, Le réseau d'Antraigues et la contre-révolution, 1791-1793, Paris, Plon, 1965, p. 73.

85.Aristide DOUARCHE, Les tribunaux civils de Paris pendant la Révolution, 1791-1800, Paris, 1907, II, p. 389 note 8 et p. 526 note.

86. Revenue d'Aix-la-Chapelle, Mme de Lamballe s'était mise à la disposition de MarieAntoinette qui lui avait octroyé un appartement aux Tuileries.

87. Robert Howell GRIFFITHS dans Le Centre perdu, Malouet et les Monarchiens dans la Révolution française, Grenoble, PUG, 1988, juge superflu d'analyser le rôle de Malouet 
dans les intrigues de la cour (p. 130) et renvoie principalement à Marcel REINHARD, La chute de la royauté: 10 août 1792, Paris, Gallimard, 1969.

88.AN, DIII 248 (11-18 mai 1792), Plainte déposée par Bertrand de Molleville et Montmorin devant Jean-Baptiste La Rivière [...] au sujet des imputations calomnieuses propagées notamment par Carra dans le Journal des Débats, par le Patriote Français et la Chronique de Paris, etc... Dans son journal, op. cit., le comte d'Espinchal parle (p. 470) de ces «fréquentes réunions, ces thés, qui donnèrent lieu à la ridicule dénonciation du comité autrichien ».

89.Sur l'affaire du Comité autrichien telle qu'elle a été évoquée à l'Assemblée, voir les Archives parlementaires (mars-septembre 1792).

90.Voir la collection de documents généralement peu exploités, publiés par la Convention nationale sous le titre Papiers trouvés aux Tuileries imprimés par ordre de la Convention, Paris, 1792 et 1793 (en particulier les 6e et 7e recueils).

91. Ce rôle de Mme Campan est confirmé par François-Dominique de Reynaud comte de MONTLOSIER (1755-1738), Souvenirs d'un émigré, 1791-1798, Paris, Hachette, 1951, p. 60.

92.Cela tend à expliquer la mort rapide en août et septembre 1792 de plusieurs témoins clés dont l'Intendant de la Liste civile La Porte, Brissac, Montmorin, Valdec de Lessart, Thierrry de Ville d'Avray, Collenot d'Angremont et également de la princesse de Lamballe qui, tous, eussent pu témoigner de la réalité de la politique de pourrissement de la Révolution mise en œuvre par les conseillers de Louis XVI et incidemment citer quelques « Janus à triple visage »- selon l'expression de Desmoulins -, comme l'était le commandant de la garde nationale Santerre, dont le nom est en effet apparu avec d'autres dans l'édition des papiers trouvés dans « l'armoire de fer ».

93.Sur la première arrestation de Mme de Grammont, née Béatrice de ChoiseulStainville, voir A. TUETEY, op. cit., tome V, p. 2684 et 2980.

94. Voir Arnaud de LESTAPIS, « Un grand corrupteur, le duc du Châtelet », Annales historiques de la Révolution Française, Paris, 1963. Voir aussi sa thèse La Conspiration de Batz (1793-1794), Paris, Société des études robespierristes, 1969.

95. Nathalie-Luce-Léontine-Joséphine de La Borde de Méréville, fille du banquier de cour, mariée en 1790 avec Arthur-Tristan-Jean-Charles-Languedoc de Noailles, duc de Mouchy, prince de Poix qui fut arrêté après le 10 Août et s'évada.

96.Tous les trois prodigieusement enrichis grâce à la Révolution.

97.Mme de Rochechouart née Durey de Morsan obtint l'acquittement du général Miranda, ou encore la comtesse de Pompignan née Beaumont intervint en faveur du comte Étienne de Mallet. Mmes de Beaufort et de Bonneval sont également souvent citées par Albert Mathiez et Arnaud de Lestapis pour l'efficacité de leur influence sur Julien de Toulouse, Alquier, Delaunay, Delacroix et les amis de Danton (voir en particulier les nombreux articles d'Albert Mathiez sur la corruption parlementaire sous la Révolution).

98.Née d'Escorailles de Fontanges, épouse de François-Gabriel Mouchet marquis de Laubespin qui fut des gentilshommes qui, avec le duc du Châtelet, accompagnèrent Louis XVI à la Législative le 10 août 1792, elle avait deux fils émigrés et demeurait rue de Grammont, $n^{\circ} 6$.

99. Diane-Adélaïde de Damas, épouse de Charles-François, comte de Simiane, marquis de Miremont, amie intime de La Fayette, recevait la même société dans son hôtel de la rue de Grenelle. Sa belle sœur, comtesse Charles de Damas, également mêlée aux intrigues contre-révolutionnaires du duc du Châtelet son oncle fut arrêtée sous la Terreur. Elle le fut à nouveau peu après la rupture de la paix d'Amiens et expulsée avec 
une cinquantaine de femmes suspectées d'activisme anti-bonapartiste (Archives de la Préfecture de Police).

100.Née de père inconnu, élevée par Mme Carotte, une femme galante qui était peutêtre sa mère, Louise-Julie Carreau fut entretenue par le prince de Soubise et elle eut deux fils reconnus par le vicomte de Ségur.

101. « Le mariage de Talma », Revue des Revues, 1er trimestre 1899, p. 202-203.

102.Ernest d'HAUTERIVE, op. cit., p. 311.

103. Wilhelm Von HumBoldt, Journal parisien, op. cit., p. 275.

104. André GAVOTY, « Une amie de Benjamin Constant, Julie Talma », Revue des Deux

Mondes, 15 décembre 1958.

105.Bibliothèque de l'Assemblée nationale, fonds Portiez de l'Oise (1793).

106.D'après les propos qu'elle recueillit en Espagne auprès de Tallien, puis auprès de Louis-Marie Prudhomme le père (1752-1830), auteur des Révolutions de Paris, dédiées à la Nation, Paris, 1789-1794, qui vint la voir au couvent de l'abbaye aux bois ; Laure Junot, duchesse d'Abrantès (1784-1838) affirme dans ses célèbres Mémoires qu'Anne Philippine Louise dite Lucile Duplessis Laridon, épouse de Camille Desmoulins, eut un «salon » fréquenté en 1792 et 1793.

107.Certaines éditrices, libraires ou imprimeuses comme les citoyennes Lesclapart, Feuchères, Momoro etc. ou des colporteuses de tracts et autres documents à caractère politique, comme la citoyenne Marcandier née Concarneau, ont certainement leur place dans l'histoire politique de la Révolution. Les dossiers et registres de police de la sous série $\mathrm{F} 7$ révèlent, pour les périodes suivantes, la participation collective et l'engagement des femmes de tous horizons, jacobines ou royalistes, à la vie politique.

\section{RÉSUMÉS}

Dans cet article, l'auteur s'appuie sur des archives et manuscrits inexploités de fonds publics et privés, diversifiant ainsi les sources imprimées qui ne se limitent pas aux mémorialistes du XIX ${ }^{\mathrm{e}}$ siècle. Le dépouillement des séries policières et judiciaires des archives permet un dénombrement exhaustif des salons politiques sous les premières législatures et il en ressort une réévaluation à la hausse du rôle politique des femmes libérales et royalistes entre 1789 et 1793.

«Cercles politiques» and «salons» at the Beginning of the Revolution (1789-1793). In this article the author uses original archives and manuscripts from public and private collections, and does not restrict himself to the writings of nineteenth century memoralists. The systematic examination of archival series of police and judicial records has made it possible to establish an exhaustive list of political salons under the first legislatures, which has led to a revaluation of the prominent political role of liberal and royalist women between 1789 and 1793.

\section{INDEX}

Mots-clés : Contre-Révolution, Olympe de Gouges, duc d'Orléans, patriotes, Auteuil, loges, républicains, royalistes 
AUTEUR

OLIVIER BLANC

Historien, conférencier, o.blanc1@wanadoo.fr 